Article

\title{
A Risk-Based Approach to Shelter Resilience following Flood and Typhoon Damage in Rural Philippines
}

\author{
Victoria Stephenson ${ }^{1, *}$, Andrew Finlayson ${ }^{2}$ (1) and Luisa Miranda Morel ${ }^{3}$ \\ 1 Department of Civil, Environment and Geomatic Engineering, London Global University, \\ London WC1E 6BT, UK \\ 2 British Geological Survey, Edinburgh EH14 4AP, UK; afin@bgs.ac.uk \\ 3 CARE International UK, London SE1 7TP, UK; mirandamorel@careinternational.org \\ * Correspondence: victoria.stephenson.12@ucl.ac.uk; Tel.: +44-(0)20-7679-7224
}

Received: 22 December 2017; Accepted: 13 February 2018; Published: 22 February 2018

\begin{abstract}
The Philippines is exposed to numerous typhoons every year, each of which poses a potential threat to livelihoods, shelter, and in some cases life. Flooding caused by such events leads to extensive damage to land and buildings, and the impact on rural communities can be severe. The global community is calling for action to address and achieve disaster risk reduction for communities and people exposed to such events. Achieving this requires an understanding of the nature of the risks that flooding and typhoons pose to these communities and their homes. This paper presents the findings from a field based case study assessment of three rural settlements in the Philippines, where typhoons and associated flooding in recent years has caused significant damage to houses and livelihoods, leading to the reconstruction of homes that more often than not reproduce similar structural vulnerabilities as were there before these hazards occurred. This work presents a methodology for risk assessment of such structures profiling the flood and wind hazards and measuring physical vulnerability and the experience of communities affected. The aim of the work is to demonstrate a method for identifying risks in these communities, and seeks to address the challenge faced by practitioners of assisting communities in rebuilding their homes in more resilient ways. The work set out here contributes to the discussion about how best to enable practitioners and communities to achieve the sought for risk reduction and especially highlights the role that geoscience and engineering can have in achieving this ambition.
\end{abstract}

Keywords: flood; typhoon; shelter; rural; disaster; risk

\section{Introduction}

\subsection{Background}

On average, 20 typhoons affect the Philippines every year, ranging in severity from annually recurring moderate events, up to extreme events such as the super-typhoon Haiyan (local name Yolanda), which affected the country in November 2013 [1]. Typhoons bring high winds, heavy rainfall, and flooding to the Philippines, causing damage to both land and property. In the case of severe events such as Haiyan, the extent of damage and destruction is significant enough to instigate an international aid response, as part of which International Non-Governmental Organisations (INGOs) seek to assist in helping communities recover from the impacts of the event.

The Sendai Framework for Disaster Risk Reduction [2] sets the current agenda of the global community for reducing the risks from disasters and calls in its first priority area for greater "understanding of disaster risk in all its dimensions of vulnerability, capacity, exposure of persons 
and assets, hazard characteristics and the environment". Calculation of risk requires measurement of the vulnerability, hazard, and exposure components of the system [3], and where losses to assets are being considered the physical interaction of the natural and man-made environments typically lead to the computation of this risk. Disasters caused by natural hazards often lead to far greater human and economic losses in low- and middle-income countries such as the Philippines [4], where impactful disaster risk reduction measures are not yet embedded or widely available to communities and people [5].

Rapid urbanisation in developing countries is generating a growing focus on understanding risk and risk reduction within this context [6], with the effects of future urban expansion on disaster risks to poor urban populations a particular concern $[7,8]$. Work focused on reducing risk in developing urban environments calls for greater synthesis in the collection and use of hazard and vulnerability data for calculating physical risk [9], with the role of geoscience in particular growing [10]. Risk assessments incorporating measures of physical vulnerability to natural hazards for rural and indigenous settlements in low and middle income countries are less frequent. Despite this community and culture are acknowledged as important components of understanding disaster risk manifestation [11], and the role of indigenous knowledge in mitigating disaster risks is further appreciated [12].

In the case of typhoon events, which manifest as wind and flood hazards, the influence of geomorphology on the characteristics of those hazards is significant. Alcantra-Ayala and Goudie present a thorough review of the role of geomorphology in disasters caused by natural hazards, including earthquakes, volcanoes, and floods [13]. Fluvial geomorphology is a direct driver of flood hazard. Slater et al. [14] demonstrate that river channel capacity and surface roughness is significant in contributing to flood hazard extent, whilst Yumul et al. [15] report that in the Philippines in 2008, artificial damming of rivers by breaching of saturated ground caused flooding from Typhoon Frank. A typhoon and its associated excessive rainfall can trigger secondary hazards such as landslides, if the geomorphological conditions promote this [16], whilst storm surges brought on by wind hazards such as in Typhoon Haiyan are being used to measure the geomorphological impact of typhoons and subsequently gauge hazard severities [17], providing an important reference for future risk assessments.

Flood hazard mapping in rural areas can be challenging due to lack of available high quality data. For example, Sanyal and Lu [18] carried out an assessment of rural communities in West Bengal and highlighted that tree cover in the settlement hindered the process of extracting robust flood inundation information. Osti et al. [19] further explore the problem of quantifying and predicting flood hazards from the perspective of flood hazard mapping in developing countries, and importantly highlight the value of community based mapping in understanding and mitigating flood risks in these contexts. Abon et al. [20] extend this to the development of community-based flood monitoring leading to an early warning system for flooding in the Philippines. More recently, the focus has been on highlighting the value of technological advancements in assisting hazard mapping capabilities [21], and within the Philippines, satellite imagery has been used to map both storm surge extent and associated building damage in the Tacloban region, as a result of Typhoon Haiyan [22]. Ongoing work is using new high-resolution topographic information in landslide susceptibility assessments [23] and in flood simulation models that are used to inform flood hazard maps [24] and use predictive rainfall scenarios to predict flood hazard [25].

Definitions of vulnerability differ widely depending on the entity being considered (human, physical, system, etc.) and the nature of the hazard to which it is exposed [26]. Physical vulnerability assessment in the context of flood and wind hazards can be carried out via a number of different means including employing anecdotal loss data, indicator methods, or more theoretical predictive strategies, as reviewed by Nasiri et al. [27] for flooding and Pita et al. [28] for hurricanes. Typically, the assessor will choose the most appropriate and feasible method for the given situation. In the context of a super-typhoon, where human loss is a significant factor, the collection of loss or damage data is not a 
priority in the post-disaster response. Likewise, the extent of destruction hinders the development of statistical damage curves for physical loss in the built environment as so much of the damage is total.

Work assessing typhoon vulnerability that applies damage assessment methods has focused on engineered structures in the Philippines, although assessments have considered the multi-hazard context of wind and flood. In the aftermath of Typhoon Haiyan, Chen et al. [29] applied a structural damage rating system to concrete framed structures in Tacloban to profile the extent of damage across the site, concluding that wind was a more significant cause of damage than flood. Hernandez et al. [30] carried out a damage survey in Leyte and Samar following Haiyan on a range of buildings including timber, concrete, and steel. Here, it is reported that the majority of non-engineered buildings surveyed suffered total collapse, whilst in engineered buildings, much of the damage was to non-structural components.

Assessments of vulnerability to typhoons have been carried out for rural housing in other countries such as India. A study by Goyal et al. [31] presented a hurricane vulnerability assessment of traditional rural houses using pre-defined damage classification and a condition assessment of the buildings incorporating construction quality and age. Meanwhile, Alam et al. [32] undertook a detailed assessment using building geometry, construction and materials to determine vulnerability in local bamboo structures in Bangladesh. Work looking at the vulnerability of rural communities in the Philippines has taken holistic approaches that include consideration of building condition and robustness. Campanero and Regaro [33] recorded whether houses were constructed of heavy or lightweight materials in their study seeking to quantify social vulnerability to Typhoon Haiyan. Usamah et al. [34] used a measure of the degree of concrete present and building geometry to indicate vulnerability to wind and flood hazards in their holistic study of housing in informal settlements in the Philippines. Resilience-based assessments of buildings exposed to flooding in developing countries are emerging [35], although not in relation to the type of traditional timber and bamboo structures prevalent in rural Philippines.

As more focus is placed on reducing disaster risk in low- and middle-income countries by investing time and resources in increasing resilience to hazards such as floods and wind, so these risk-based approaches will become more developed and available. So far, good progress is being made in both measuring and communicating flood hazard in these communities, but much work is still to be done. Two critical factors in this are the consideration of local and indigenous knowledge in understanding hazards and furthering understanding of the relationship of geoscience with those communities to achieve this end. From the perspective of physical vulnerability, there is a growing focus on non-engineered and vernacular structures in relation to typhoon, flood, and wind hazards, with some key outputs developing in terms of both engineering assessment and the role this plays in holistic societal resilience to these disasters. Further progress in this is needed to reduce epistemic uncertainty surrounding the response of these structures to flood and wind loads, which ongoing research is addressing [36].

As this progress continues, the outputs will be available to those whose role is increasingly to deliver risk reduction in low- and middle-income countries, not least the shelter practice community hosted within NGOs and international aid institutions [37]. Within the context of shelter aid, practitioners focus on helping communities and householders recover through providing physical assistance in the form of materials and, increasingly, cash [38]. Beyond this, additional assistance on best practices for rebuilding houses is often provided, delivered in the form of "Build Back Safer" (BBS) key messages [39] and promoted through various strategies, including poster presentation, and community-based education and training. Early work from the global engineering community focused on developing countries [40] sets out much of the foundations for the key messages used today. The messages are designed to provide basic construction advice that can be understood by people without an engineering or technical background but also consider contextually appropriate, affordable, and available local materials [41]. 
Messages are often focused on structural vulnerability, and little consideration is given to the nature of their environmental setting. In many contexts, this renders them inadequate [42] and unable to support the rapidly changing needs, priorities, and capacities of disaster affected populations. The role of geosciences in post-disaster recovery is significant in understanding rapid environmental change caused by disasters, mapping hazards, and predicting future risk. From a humanitarian perspective, hazard and risk reduction awareness plays a significant role in people's capacities to recover over time and reduce risk to future hazards, and the sector is actively seeking to embed risk approaches into the provision shelter support. For example, disaster-affected communities often face frequent and varying hazards at the same time that can delay housing recovery and inhibit and influence the impact of guidance provided by the humanitarian community [43].

The uptake of BBS messages once communicated has been a challenge for the sector [44]. It is widely accepted that a greater understanding of effective communication and behavior change mechanisms need to be explored, as well as understanding the multiple external factors that affect reconstruction decisions of disaster-affected households. Framing responses to this challenge in the context of understanding and communicating risk is fundamental to achieving progress. Work to this end is being carried out to improve capacity to develop such messages in an efficient and timely manner despite the difficulties of post-disaster environments [45]. Nonetheless, research into building back safer clearly states that developing context-appropriate, effective, applicable and timely safer reconstruction advice requires significant involvement from multiple disciplines, including expertise on environmental hazards and engineering [46].

\subsection{Research Aims}

In light of this state of progress of knowledge and application of geoscience and engineering to the understanding and delivery of disaster risk reduction, the authors here present an approach to measuring risk for inland rural communities in the Philippines exposed to wind and flood hazards from typhoons. The aim of the work is to highlight through case study demonstration how hazard data and severity indices can be combined with rapid physical vulnerability assessments to produce a measurable scale of risk within the spatial context of a settlement. The work draws on existing flood hazard mapping tools for the Philippines and combines this with a site-deployable physical vulnerability index which has been applied to three villages in the island of Leyte.

In the following sections, a description of the methods applied is given (Section 2), followed by a presentation of the results of the hazard and vulnerability assessments (Section 3). The discussion focusses on how the approach could potentially contribute to delivering disaster risk reduction in low and middle income countries that are exposed to typhoons, such as the Philippines. The steps required to continue to integrate the role of geoscience and engineering into risk reduction interventions in these contexts are explored and how best to meet the needs of an evolving shelter practice that aspires to provide an inter-disciplinary approach to promoting resilience in disaster-affected communities.

\section{Methodology}

\section{The Case Studies}

In March 2017, the authors, a team comprising a geomorphologist, engineer, and shelter researcher, visited three rural communities on the eastern side of the central volcanic uplands of Leyte: Badiangay, Plaridel, and Calabnian (Figure 1). The selection of the sites was made through considering rural community locations where shelter assistance from NGOs had been given over an extended period of time in the three and a half years following Typhoon Haiyan, in the form of expert advice, training, cash, and material support. This offered the opportunity to survey buildings that had become permanent homes in the wake of the disaster and therefore are suitable for consideration in the context of measuring long-term risk and resilience. The buildings were not assessed against any degree of BBS message uptake but rather a visual assessment of the structures that recorded their features without 
any bias, as the influence of message uptake on shelter vulnerability is at this stage beyond the scope of the work.

The three sites were each visited for one day, in which multiple methods of data collection were applied. In the field, transect walks with community members were undertaken in each location. These transect walks provided an opportunity to speak to community members about their knowledge and awareness of their surrounding environment and hazard context. During the walks, community members pointed out areas that they perceived to be susceptible to different hazards and spoke about their experience of typhoon Haiyan in terms of damage caused to land and property. Focus groups provided opportunity for more detailed discussion regarding the hazards experienced at the sites, where timelines were constructed for extreme and severe weather events that had been experienced within the community's living memory.

A photographic record of each location was built up during the walks, focusing on reconstructed shelters present in the communities and natural features that informed an understanding of the nature of the hazards. The geomorphological context for each community was further investigated using $30 \mathrm{~m}$ and $90 \mathrm{~m}$ resolution Shuttle Radar Topography Mission (STRM) elevation datasets (Global 1-arc version 3, and global 3-arc version 3, after NASA JPL [47,48]). Satellite imagery, available through Google Earth, was also collated, with pre- and post-event images providing a useful means to assess the impact of the hazards on homes and on the landscape (e.g., Figure 2).

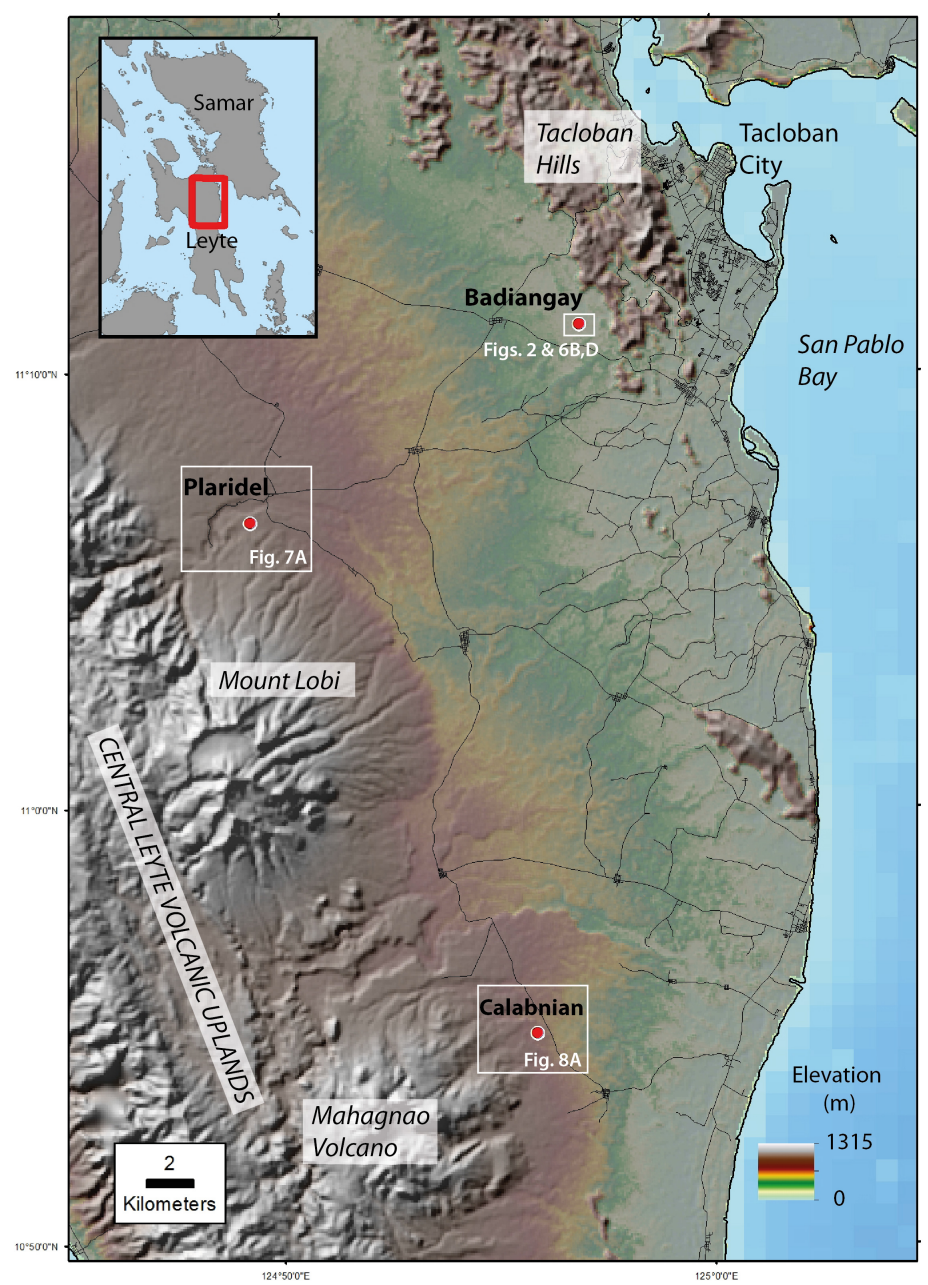

Figure 1. Location of the three case studies in the Philippines on the island of Leyte to the South-West of Tacloban, where typhoon Haiyan made landfall. The background elevation data is from NASA Shuttle Radar Topography Mission (STRM) [48]. 

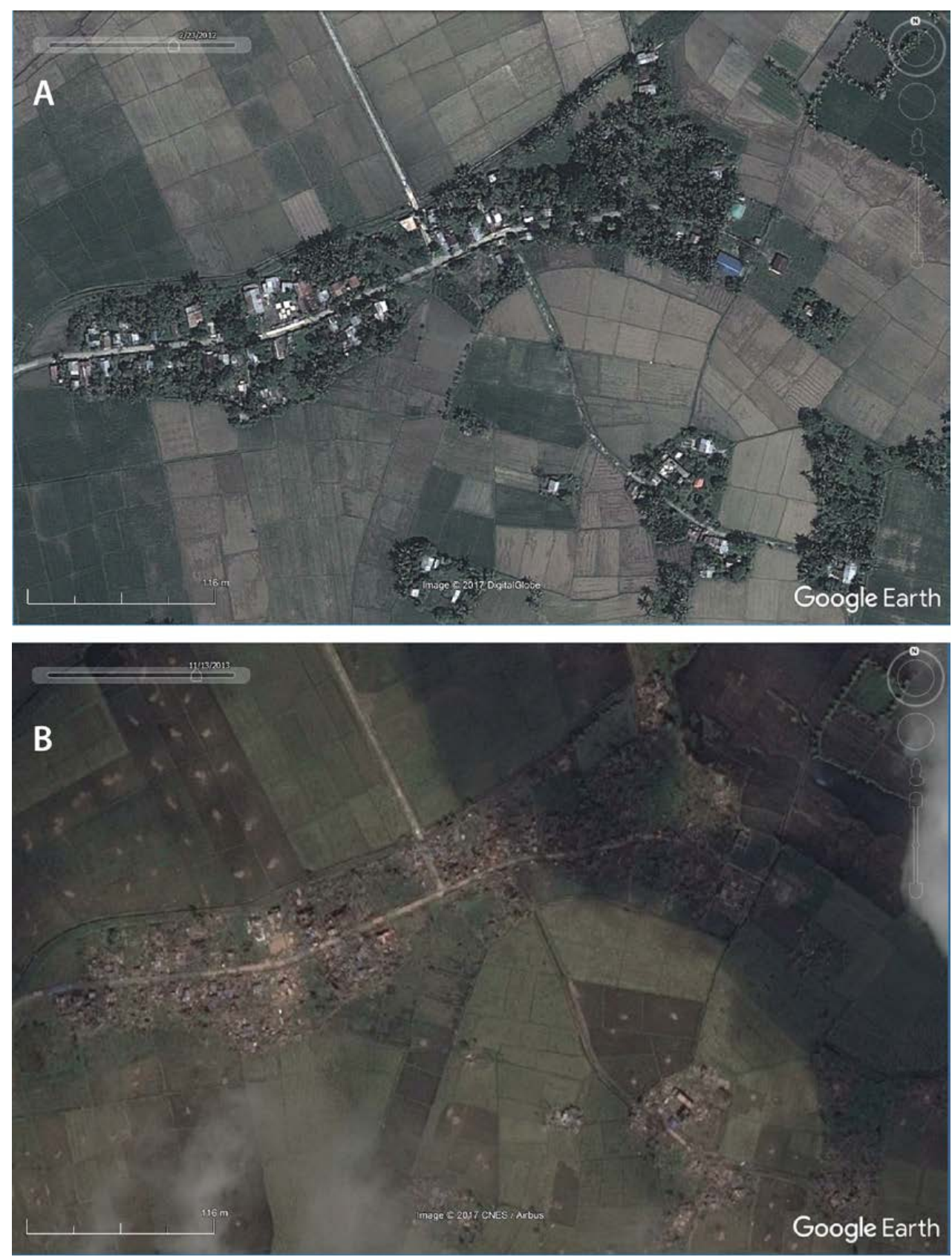

Figure 2. (A) Digital Globe image (23 February 2012) courtesy of Google Earth showing the community of Badiangay prior to Typhoon Haiyan. (B) CNES/Airbus image (13 November 2013) courtesy of Google Earth showing the community five days after Typhoon Haiyan passed through.

Both nationally produced data and local community knowledge were used in order to produce a hazard profile for each site. The geographical and hazard context for each community is presented in the next section, and these characteristics are schematically illustrated in Figure 3. In addition to the external hazard data, community perceptions of flood hazard and experiences of flood events offer important context to the design of the risk-based model for supporting recovery. These insights offer confirmation of the nature of the hazard that is shown in maps and enrich the context in which practitioners are able to assist in the recovery process. Key observations and perceptions of community members are also discussed in the following section. 


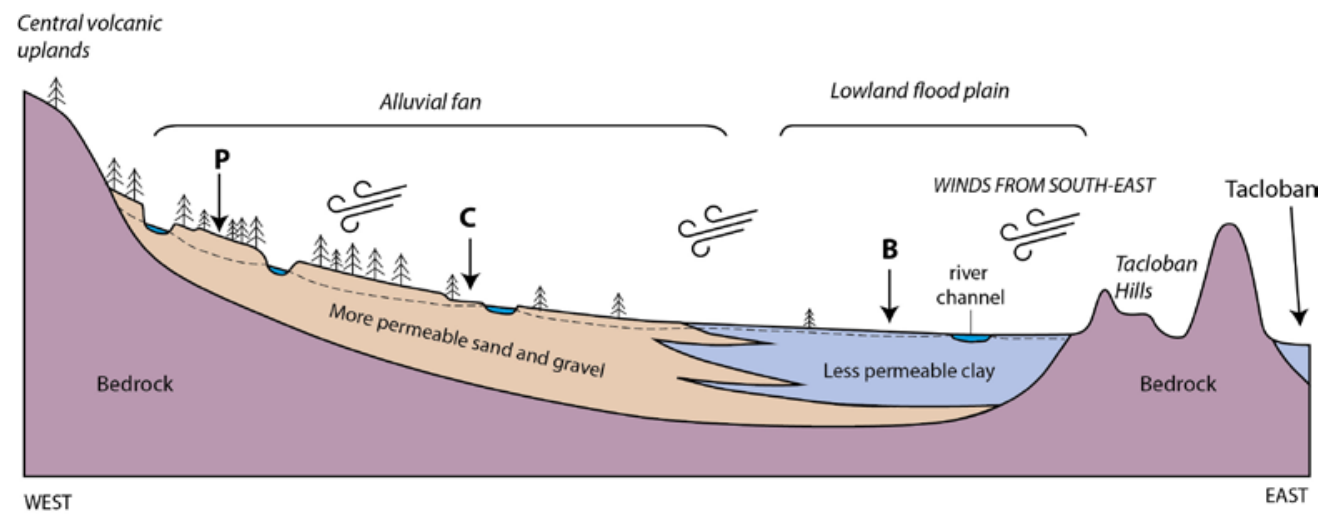

Figure 3. Vertically exaggerated schematic cross section to show the geographical context and simplified geology of the communities investigated in this study. P: Plaridel, C: Calabnian, B: Badiangay. The dashed line represents groundwater level.

Across the sites, the buildings were typically constructed of a timber frame and clad with either bamboo or other timber (Figures 8 and 9). In most cases, the cladding panels were permeable, being made of traditional woven palm or bamboo lath. Roofs were either gable-ended or hipped, and it was common for the upper portion of the façade to be open to allow roof-level ventilation (Figures 4 and 5). At ground level, shelters often included a raised floor, providing a storage area beneath the house (Figure 4). Foundations were predominantly formed of posts dug into the ground or, in some cases, a concrete slab was present (Figure 5).

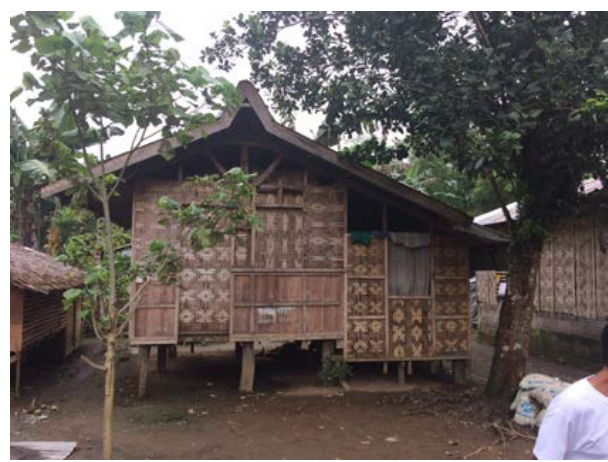

Figure 4. Example house from Calabnian showing woven palm façade, roof level ventilation, raised ground floor, and sunken post foundations.

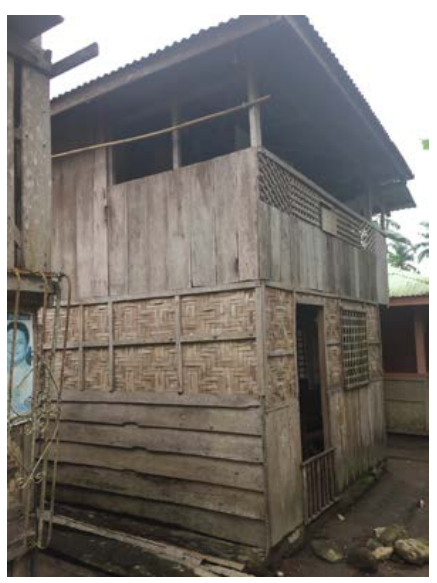

Figure 5. Example house from Plaridel showing timber façade, hipped roof, and concrete slab base. 


\section{Results}

\subsection{Profiling the Hazards}

The two hazards considered in this study are flooding and high winds associated with the effects of typhoons in low relief, inland landscapes. Other non-hydrometeorological hazards (e.g., earthquakes) are not considered in this work. The Mines and Geosciences Bureau 1:10,000 scale flood hazard maps [49-52] indicate areas of low, moderate, high, and very high flood susceptibility. Each category is associated with a range of likely flood heights and durations associated with prolonged and heavy rains, and a general description of the topography and geomorphology in the area (Table 1). These maps were downloaded from the MGB website and can also be viewed via an online map viewer (http:/ / gdis. mgb.gov.ph/mgbpublic/). In addition, the Nationwide Operational Assessment of Hazards (Project NOAH) has produced flood inundation maps based on simulations of a 100 year return rainfall event for Leyte. The NOAH maps were viewed on a web-GIS viewer (http:/ / noah.dost.gov.ph/\#/) and open data GIS files were downloaded from the NOAH website (http:/ / center.noah.up.edu.ph/resources). The NOAH maps give a range of inundation heights and identify zones with different modelled hazard levels [24] (Table 1).

Table 1. Flood hazard levels derived from Mines and Geosciences Bureau (MGB) and Project NOAH maps. The rating for risk matrix column on the right hand side attempts to merge these hazard levels into simple high (H), medium (M), and low (L) scores so they can be combined within the risk matrix (Figure 15).

\begin{tabular}{|c|c|c|c|c|c|}
\hline Source & Hazard Level & Flood Height & $\begin{array}{c}\text { Flood } \\
\text { Duration }\end{array}$ & Topography & $\begin{array}{l}\text { Rating for } \\
\text { Risk Matrix }\end{array}$ \\
\hline \multirow{4}{*}{$\begin{array}{l}\text { MGB 1:10K flood } \\
\text { hazard maps }\end{array}$} & Low susceptibility & $\leq 0.5 \mathrm{~m}$ & $\leq 1$ day & Low hills, gentle slopes. & $\mathrm{L}$ \\
\hline & $\begin{array}{c}\text { Moderate } \\
\text { susceptibility }\end{array}$ & $0.5-1 \mathrm{~m}$ & $1-3$ days & $\begin{array}{l}\text { Fluvial terraces, alluvial } \\
\text { fans, infilled valleys. }\end{array}$ & M \\
\hline & High susceptibility & $1-2 \mathrm{~m}$ & $\geq 3$ days & $\begin{array}{l}\text { Active river channels, } \\
\text { along river banks. }\end{array}$ & $\mathrm{H}$ \\
\hline & $\begin{array}{c}\text { Very High } \\
\text { susceptibility }\end{array}$ & $\geq 2 \mathrm{~m}$ & $\geq 3$ days & $\begin{array}{l}\text { Active river channels, } \\
\text { along river banks. }\end{array}$ & $\mathrm{H}$ \\
\hline \multirow{3}{*}{$\begin{array}{l}\text { NOAH } 100 \text { year } \\
\text { return flood model }\end{array}$} & 1 & $\leq 0.5 \mathrm{~m}$ & - & - & $\mathrm{L}$ \\
\hline & 2 & $0.5-1.5 \mathrm{~m}$ & - & - & $\mathrm{M}$ \\
\hline & 3 & $\geq 1.5 \mathrm{~m}$ & - & - & $\mathrm{H}$ \\
\hline
\end{tabular}

A quantitative indication of wind hazard is available from the multi-hazard building suitability map for Leyte, produced by Deutsche Gesellschaft für Internationale Zusammenarbeit (GIZ) $\mathrm{GmbH}$ [53]. These authors used modelled regional (30 $\mathrm{km}^{2}$ raster resolution) maximum wind speeds (sustained for three seconds) with return intervals of 50, 100, 250, 500, and 1000 years, which are available as GIS files from the Probabilistic Risk Assessment (CAPRA) Programme (http:/ / risk.preventionweb.net/capraviewer). The regional CAPRA values were then adjusted to site-specific wind speeds using a factor based on land cover, surface slope, and aspect [53].

\subsubsection{Badiangay}

Badiangay is located on flat (slope of $<0.2^{\circ}$ ), low-lying ground (approximately $10 \mathrm{~m}$ above sea level (a.s.1.)), which forms the flood plain of Bangton River (Figure 6). The eastern edge of Badiangay is approximately $400 \mathrm{~m}$ away from the river. The soil is naturally clayey, and during the field visit (March 2017), standing water was observed in many of the surrounding rice fields. The main road through the community, and many of the houses, are built on a narrow strip of artificially elevated ground consisting of cobbles, gravel, and sand (locals indicated that these materials were brought in from elsewhere by truck), which helps reduce vulnerability to the local flood hazard (Figure 6a). Many of the houses are clustered closely together on, and adjacent to, this strip of ground. 

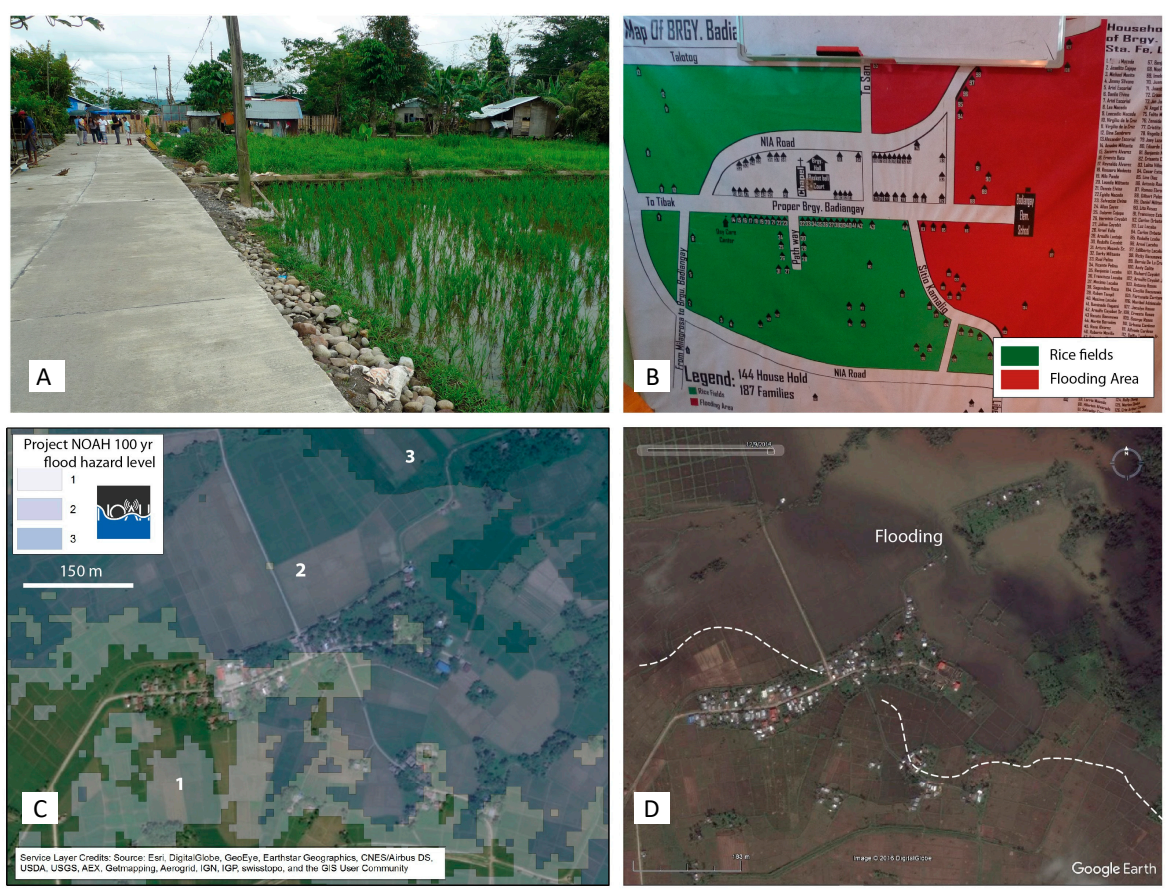

Figure 6. (A) Badiangay occupies flat ground along the flood plain of the Bangon River. The main road through the community and the adjacent houses are built upon a narrow strip of artificially elevated ground comprising cobbles, sand, and gravel, which has been brought into the area. (B) Project NOAH flood hazard levels associated with a 100-year return rainfall event. Base map provided by ESRI (C) Community developed map showing areas of flooding based on the community's experience. (D) Extent of flooding following heavy rainfall associated with Typhoon Hagupit (2014). DigitalGlobe image captured on 9 December 2014, courtesy of Google Earth.

Badiangay is built upon ground mapped by MGB as having a high to moderate susceptibility to flooding. The Project NOAH 100 year flood map suggests an increasing hazard level from zero to the west of the community up to 3 in the eastern side (Figure 6b). The CAPRA regional 50-year return period maximum wind speed is $209 \mathrm{~km} \mathrm{~h}^{-1}$. Given the expansive open ground around Badiangay, the adjustment factor applied by GIZ [53] has limited impact on the modelled local 50 year return wind speed, which is $195 \mathrm{~km} \mathrm{~h}^{-1}$. Although Badiangay lies to the west of the Tacloban Hills, the height of the hills is probably insufficient, and the distance from the foot of the hills it too far, for the community to be offered shelter from typhoon winds.

The community recounted the severe extent of damage to buildings that was caused by high winds during Typhoon Haiyan in 2013. 125 out of 128 houses were totally or partially damaged (Figure 2a,b) during the event. In addition to the wind hazard, the community experienced 'knee deep' to 'waist deep' flooding. Flooding was also highlighted as a hazard that impacts the community on a regular basis: "we experience flooding every year ... water can stay high for several days". The community's own experience of the flood hazard is expressed in their community-developed map, which highlights a high level of hazard in the eastern side of the community (Figure 6c). The map, and the spoken accounts from individuals in the community, support the assigned hazard levels and descriptions in both the MGB and Project NOAH Maps. The spatial pattern of flooding shown in the Project NOAH map also correlates well with the flood extent observed from satellite imagery following heavy rainfall associated with Typhoon Hagupit in 2014 (Figure 6b,d). As a result of the high level of flood hazard in the community (particularly in the eastern end) many individuals expressed a desire to add a second floor to their homes: "When it floods, people put belongings on the second floor or build temporary stores up high", "Last December flooding reached head height, so I want a two-storey house". 


\subsubsection{Plaridel}

The community of Plaridel (130 m a.s.l.) is developed upon an alluvial fan that extends out from the volcanic hills to the west. The surface of the fan slopes very gently toward the north-east at an average angle of approximately $1.5^{\circ}$. The center of the community is located approximately $400 \mathrm{~m}$ from the Binahaan river to the north and approximately $100 \mathrm{~m}$ from the smaller Panda river to the south. Both these rivers are incising into the alluvial fan, with Plaridel sitting on an elevated terrace in between (Figures 3 and 7). The soil is a sandy loam. During the field visit, locals said that their pump well reaches a depth of $25 \mathrm{~m}$ and that the subsurface material to that depth mostly consists of sand.

Plaridel is built upon ground mapped by MGB as having zero to low flood susceptibility. The Project NOAH 100-year flood map suggests that most of the community has no flood hazard, with a small area in the east exposed to a level 1 hazard (Figure 7). The CAPRA regional 50 year return period maximum wind speed is $207 \mathrm{~km} \mathrm{~h}^{-1}$, and the adjusted local wind speed that is shown in the maps produced by GIZ [53] is somewhat lower $\left(165 \mathrm{~km} \mathrm{~h}^{-1}\right)$, reflecting the influence of forest cover.

In Plaridel, damage to housing during Typhoon Haiyan was almost entirely caused by wind, with the majority of the shelters requiring extensive or complete rebuilds after the event. During the focus group discussions, community members indicated that water levels locally reached knee depth but lowered quickly after. The well-drained sand and gravel below the community (Figure 3) means that prolonged flooding is unlikely to occur: "the water only stays high for one hour-we are not flood prone". The community is aware of its position in relation to the surrounding environment and how this reduces the flood hazard that they are exposed to: "the ground is higher here than in other areas ... no one lives in areas that get washed out". These observations describing a relatively low flood hazard are consistent with patterns shown in the flood hazard maps produced by Project NOAH (Figure 7) and MGB [52]. However, it is worth noting that, while the community escapes direct flooding, it is still impacted by flood waters cutting off access and isolating it: "Even though when the rivers are high we are safe, we still get trapped".

\subsubsection{Calabnian}

The geographical context for Calabnian is somewhat similar to Plaridel. Calabnian (approximately $50 \mathrm{~m}$ a.s.l.) is also developed on an alluvial fan, which slopes gently (approximately $1.5^{\circ}$ ) towards the east. The community is bounded by rivers $500 \mathrm{~m}$ to the north, and $100 \mathrm{~m}$ to the south. However, unlike Plaridel, Calabnian is not developed on a prominent terrace on the alluvial fan surface; and the ground surface is closer to the elevation of the river that flows past the southern edge of the community (Figures 3 and 8). The soil is a sandy loam. During the field visit locals indicated that sands continue to at least $6 \mathrm{~m}$ below the surface (the depth of one of their pump wells).

The 1:10,000 scale MGB maps assign zero to low flood susceptibility for the northern side of Calabnian; however, the southern half of the community is assigned a moderate flood susceptibility. Similarly, the NOAH 100-year flood hazard is zero in the north-western side of Calabnian and level 3 in the southern side he community (Figure 8b). The CAPRA regional 50-year return period maximum wind speed is $203 \mathrm{~km} \mathrm{~h}^{-1}$. The adjusted local wind speeds calculated by GIZ [53] vary from $141-189 \mathrm{~km} \mathrm{~h}^{-1}$. This variation is largely a result of the patchwork of more open and forested areas around the community.

In Calabnian, the community recounted several episodes of flooding; these have been particularly focused around the south-eastern side of the community. During Typhoon Haiyan flooding was considered a cause of damage alongside the high winds-particularly in the south-eastern edge of the community. One community member observed that "the river moved during Yolanda (Haiyan)", perhaps describing where the river rose to flow along new (usually dry) channels-one of which is occupied by houses in the southern edge of the community (Figure 8b). Although flooding in this area is relatively frequent, it appears rarely to be prolonged: "flooding doesn't last more than 1-2 days". The general accounts of flooding in the south-eastern side of the community are in agreement with the moderate to high flood hazard indicated on Project NOAH (Figure 8b) and MGB maps [51]. 


\subsubsection{Wind and Flood Hazard: Site Comparison}

The flood hazard designations demonstrate that even at the scale of a single village flood hazard can fluctuate, highlighting that within the same community certain villagers will be more or less at risk from a given flood event. On the MGB maps, the flood hazard in Calabnian and Plaridel ranges from 'low' to 'moderate' in the areas where buildings are present. This corresponds to flooding of up to $1 \mathrm{~m}$ depth with maximum duration of three days. Meanwhile in Badiangay, a more significant flood hazard range of 'moderate' to 'high' exists, which would expose buildings to flood depths of up to $2 \mathrm{~m}$, for durations in excess of three days. These rapidly identifiable levels of flood hazard give immediate context to any post-disaster assessment of shelter reconstruction that seeks to reduce future risk. For example, repositioning of reconstructed buildings in Plaridel and Calabnian in areas where only 'low' hazard was present would potentially reduce likely future damage. Meanwhile in Badiangay, the relatively severe flood hazard would identify a need to prioritise incorporating flood-resilient design into reconstructed shelters, such a raising floor levels.

The maximum wind speed profiles for each of the sites in this study are shown in Figure 9. Badiangay and Calabnian are exposed to relatively similar wind speed profiles, whilst that in Plaridel is lower by approximate $14 \%$ across the range of return periods. This is largely a result of the higher surface roughness in Plaridel caused by increased tree cover, which can act to reduce wind speed [53]. In each location, the maximum recorded wind speed felt in the Philippines during typhoon Haiyan $\left(315 \mathrm{~km} \mathrm{~h}^{-1}\right)$ rates as a return period of between 400 (Badiangay) and 1000 (Plaridel) years, a more typical 100-year return period wind speed for these locations is around $200 \mathrm{~km} \mathrm{~h}^{-1}$.

\subsection{Building Vulnerability Assessment}

The aim of the design of the vulnerability assessment is to enable a meaningful measure of vulnerability to be ascertained within the context of post-disaster assistance strategies. This relies on visual measures of vulnerability that can feed into simple classification procedures and ultimately be communicated as advice to communities. Detailed geometric surveying and material analysis for example would be inappropriate for this approach, although more detailed assessments would benefit from such data. At this level of assessment, simple physical models of loading and structure response can be considered in relation to the building to ascertain a relative measure of vulnerability dependent upon architectural features of the design of the structure.

A simple numerical scale of building vulnerability to flooding was developed by Stephenson and D'Ayala [54] specifically for historic structures, which has since been applied in the Philippines for heritage buildings within a multi-hazard context [55]. The work presented here uses a similar approach to the study of traditional rural housing in the Philippines, understood as non-engineered vernacular buildings. Across the case studies, rapidly assessable external building features were identified that were common to the shelters constructed in these rural locations. The internal features were not considered, neither were detailed structural indicators such as diagonal bracing as this level of detail goes beyond the scope of this initial assessment approach.

These features form the basis of the vulnerability indicators, with the rating scale derived using simple mechanical indicators for increased likelihood of damage to the structure by floodwater or wind pressure. For each hazard case, three indicators were used, with either a numeric scale or binary option in each case. The options in each indicator are then translated into a numeric vulnerability factor (VF) on a normalised scale from 0 to 1 following the method previously set out in Stephenson and D'Ayala [54]. Figure 10 schematically depicts the indicators and how they contribute to vulnerability in relation to the hazards, whilst Table 2 describes the indicators and the rationale for their contribution to damage and loss in the building.

In the case of flood hazard, the effect of lateral pressure from floodwater is considered in relation to the resistance of the structure to being washed away, and the impact of floodwater inundation on building materials and belongings with raised floors and second storeys is considered to reduce vulnerability in this respect. Flood inundation of materials is typically the first stage in a damage 
scale derived for flood hazards [56], and its incorporation here offers the opportunity to produce an assessment that is distributed in nature and covers a broader scale of vulnerability extents. In relation to wash out, the connection of the structure to the foundation is a significant factor, and in the aftermath of Typhoon Haiyan surveys reported these to be very poor [42]. Additionally, a lack of connection between stone foundation and post is employed in the Philippines as a mitigation against earthquake shaking hazard [57]. In this model, limited or no mechanical connection is assumed between the timber frame and either slab or post foundation, with only the friction action of the embedment of the post considered to resist flood loading and provide vulnerability reduction.

In the case of wind hazard, the roof design and shape is considered in relation to the local pressures around the structure; this focus in part being driven by a predominance for roof damage as a result of typhoons [58]. Wind tunnel tests have shown that hipped roofs can reduce peak suction pressure by up to $42 \%$ when compared to gable roofs in low-rise buildings [59]. They are considered less vulnerable than gable structures due to their ability to deflect wind load and resist the increase of wind pressure at the edges, such as occurs in gable roofs. Likewise, larger overhangs have been shown to lead to increased roof pressures, even in hipped roofs [60], and these are considered to increase vulnerability. Finally, the presence of a roof level vent, to permit wind to pass through a structure more easily is considered to reduce the vulnerability, based on the principle that large openings located opposite to each other on a building façade reduce overall wind pressure coefficients [61].
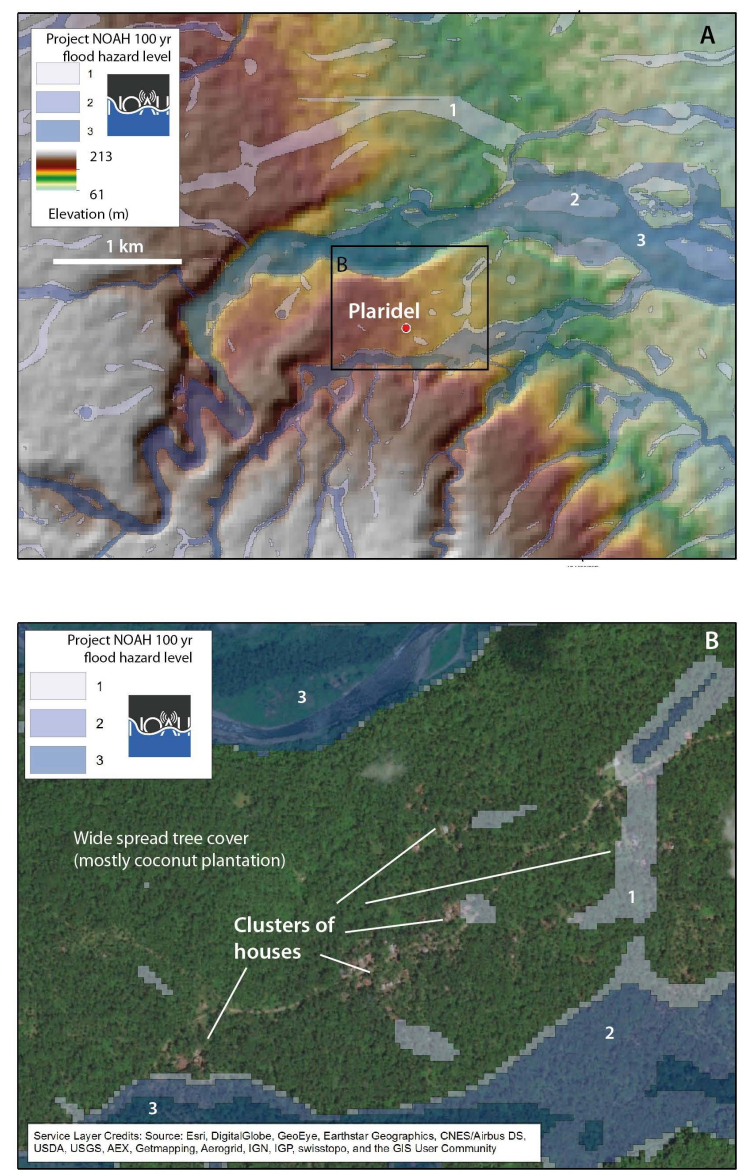

Figure 7. (A) Plaridel sits on an elevated terrace, which has developed during the Holocene as the Binahaan river to the north and Panda river to the south have incised to lower levels. Much of the terrace lies above modelled flood levels. Elevation model derived from NASA SRTM [60]. (B) Satellite image of Plaridel showing spread out housing and dense tree cover. Base map provided by Environmental Systems Research Institute (ESRI). The flood hazard levels in both images $(\mathbf{A}, \mathbf{B})$ are taken from the Nationwide Operational Assessment of Hazards (Project NOAH) 100-year return event. 

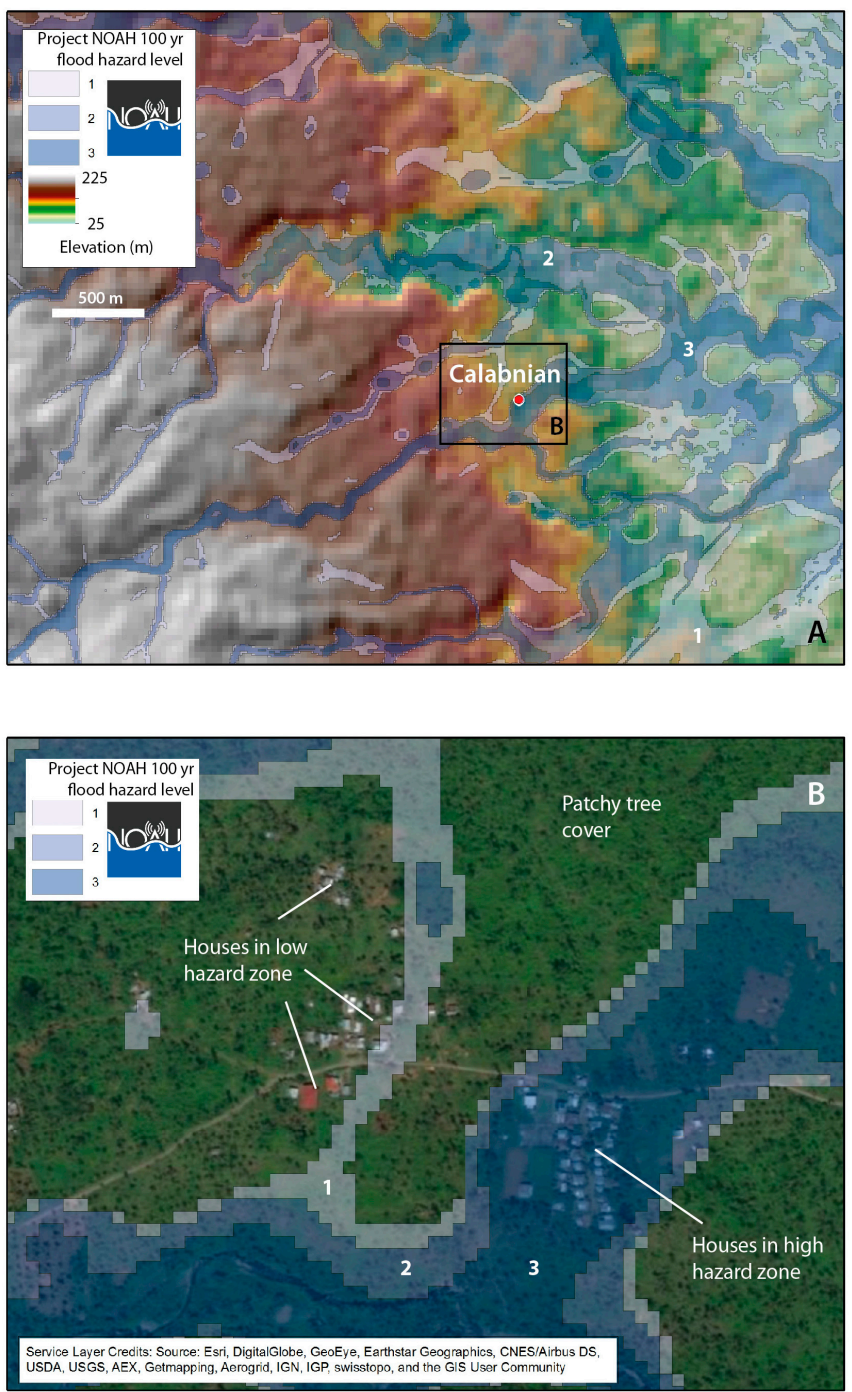

Figure 8. (A) Calabnian is located close to the edge of a low terrace between rivers located to the north and south. Elevation model derived from NASA SRTM [60]. (B) Satellite image of Calabnian showing housing clusters in high and low hazard zones. Base map provided by ESRI. The flood hazard levels in both images (A,B) are taken from the Project NOAH 100-year return event.

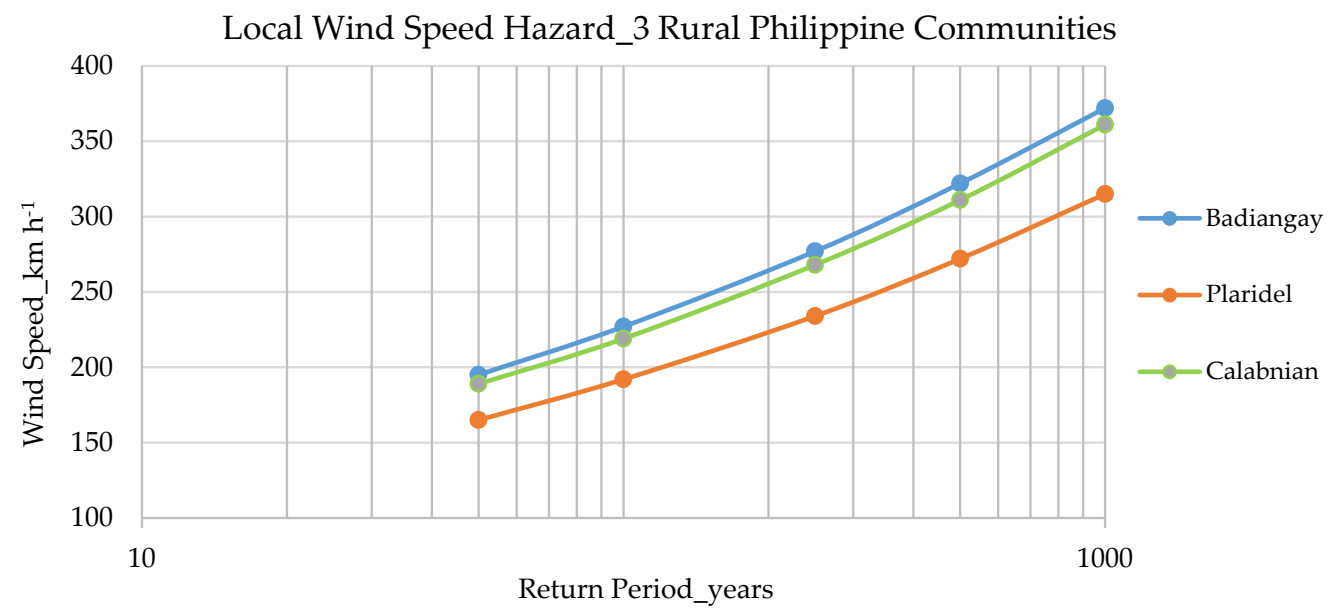

Figure 9. Wind speed hazard curve derived from [22]. 


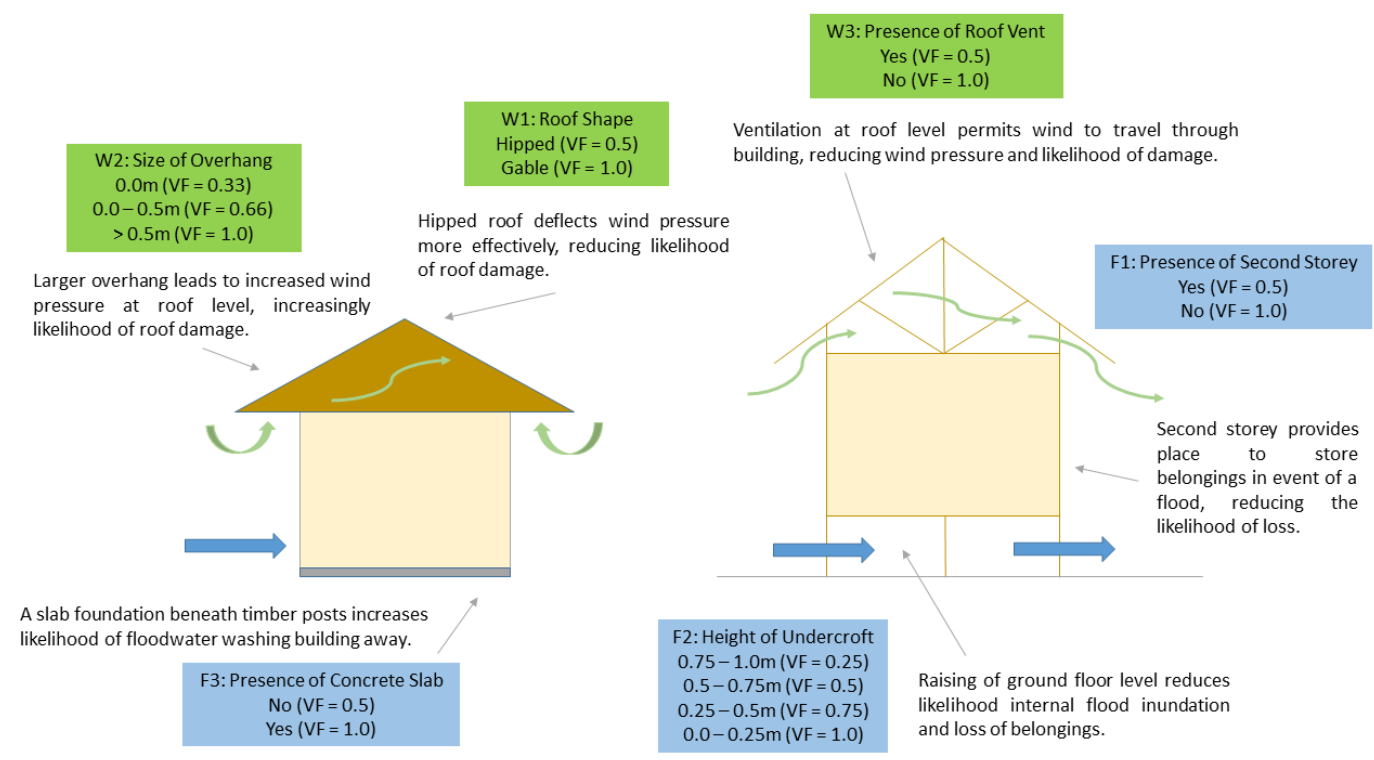

Figure 10. Schematic of vulnerability indicators showing mechanical processes in relation to flood and wind hazards and traditional rural Philippine building features. Vulnerability factors (VF) are given for different options relating to each indicator.

Table 2. Description of vulnerability indicators for flood and wind hazard.

\begin{tabular}{ccccc}
\hline Hazard & Indicator & Indicator No. & Options & Description \\
\hline & $\begin{array}{c}\text { Presence of } \\
\text { Second Storey }\end{array}$ & F1 & Yes, No & $\begin{array}{c}\text { Presence of second storey provides a place to } \\
\text { store belongings in event of a flood, reducing } \\
\text { the likelihood of loss. }\end{array}$ \\
\cline { 2 - 5 } & $\begin{array}{c}\text { Raising of } \\
\text { Ground Floor }\end{array}$ & F2 & $\begin{array}{c}0.0-0.25 \mathrm{~m}, 0.25-0.5 \mathrm{~m}, \\
0.5-0.75 \mathrm{~m}, 0.75-1.0 \mathrm{~m}\end{array}$ & $\begin{array}{c}\text { Raising of ground floor level reduces } \\
\text { likelihood of flooding and loss of belongings. }\end{array}$ \\
\cline { 2 - 5 } & $\begin{array}{c}\text { Presence of } \\
\text { Concrete Slab }\end{array}$ & F3 & Yes, No & $\begin{array}{c}\text { A slab foundation beneath timber posts } \\
\text { increases likelihood of floodwater washing } \\
\text { building away. }\end{array}$ \\
\hline Wind & Roof Shape & W1 & Gable, Hipped & $\begin{array}{c}\text { Hipped roof deflects wind pressure more } \\
\text { effectively, reducing likelihood of roof damage. }\end{array}$ \\
\cline { 2 - 5 } & Overhang & W2 & $0.0,0.0-0.5 \mathrm{~m},>0.5 \mathrm{~m}$ & $\begin{array}{c}\text { Larger overhang leads to increased wind } \\
\text { pressure at roof level, increasing likelihood of } \\
\text { roof damage. }\end{array}$ \\
\cline { 2 - 5 } & Roof Vents & W3 & Yes, No & $\begin{array}{l}\text { Ventilation at roof level permits winds to travel } \\
\text { through the building, reducing wind pressure. }\end{array}$ \\
\hline
\end{tabular}

For each hazard case, the indicators are described here in Table 3 for flood and Table 4 for wind. Suitable numeric bands were selected for indicators F2 and W2 in order to promote rapid visual assessment, and without the need for a detailed survey. This was to promote feasible undertaking of the assessment by international agencies working in disaster recovery contexts seeking to apply vulnerability-based assessments.

For each of the three communities, photographic records were used to assign exemplar buildings with a vulnerability factor for each category. Examples are shown in Figures 11 and 12 of relatively less and more vulnerable buildings. This method of presentation offers an overview of the typology of building that has been classified as more or less vulnerable according to this methodology. The annotated photographic records provide pictorial information to convey the potential vulnerabilities to homeowners. This offers an opportunity to facilitate more successful communication with communities. The pictorial records can be used to show less and more resilient reconstructed shelters, which can be promoted or discouraged by practitioners assisting with recovery. As they are linked directly to 
existing buildings and building practice on the site, they promote already existing building practices that can produce safer housing and risk reduction. Building on this, photographic records accumulated over time across sites will allow for the verification and aggregation of typologies and their associated vulnerability ratings, offering the future opportunity to assess the vulnerability at larger geographical scales with robust statistical techniques.

Table 3. Vulnerability scale for flood hazard.

\begin{tabular}{ccc}
\hline Indicator & Options & Vulnerability Factor \\
\hline \multirow{2}{*}{ F1 } & Yes & 0.5 \\
& No & 1.0 \\
\hline \multirow{2}{*}{ F2 } & $0.75-1.0 \mathrm{~m}$ & 0.25 \\
& $0.5-0.75 \mathrm{~m}$ & 0.5 \\
& $0.25-0.5 \mathrm{~m}$ & 0.75 \\
& $0.0-0.25 \mathrm{~m}$ & 1.0 \\
\hline \multirow{2}{*}{ F3 } & No & 0.5 \\
& Yes & 1.0 \\
\hline
\end{tabular}

Table 4. Vulnerability scale for wind hazard.

\begin{tabular}{ccc}
\hline Indicator & Options & Vulnerability Factor \\
\hline \multirow{2}{*}{ W1 } & Hipped & 0.5 \\
& Gable & 1.0 \\
\hline \multirow{2}{*}{ W2 } & 0.0 & 0.33 \\
& $0.0-0.5 \mathrm{~m}$ & 0.66 \\
& $>0.5 \mathrm{~m}$ & 1.0 \\
\hline \multirow{2}{*}{ W3 } & Yes & 0.5 \\
& No & 1.0 \\
\hline
\end{tabular}

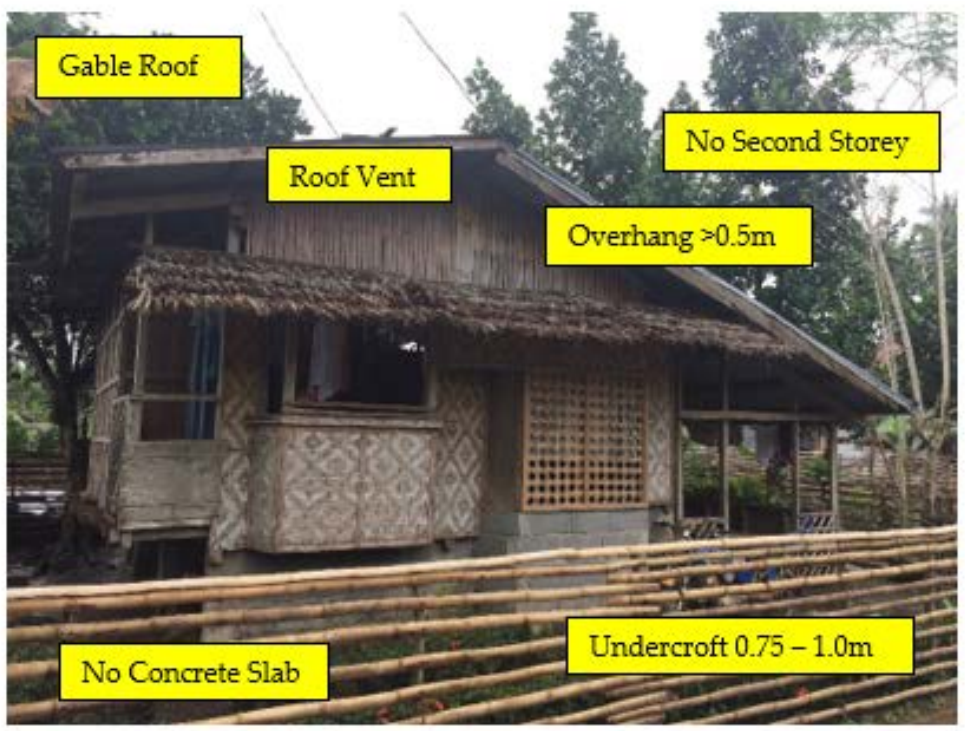

Vulnerability Ratings

F1: 1.0

F2: 0.25

F3: 0.5

Cum_Flood: 0.58

W1: 1.0

W2: 1.0

W3: 0.5

Cum_Wind: 0.83

Total Vulnerability: 0.71

Figure 11. Example low vulnerability shelter from Calabnian. 


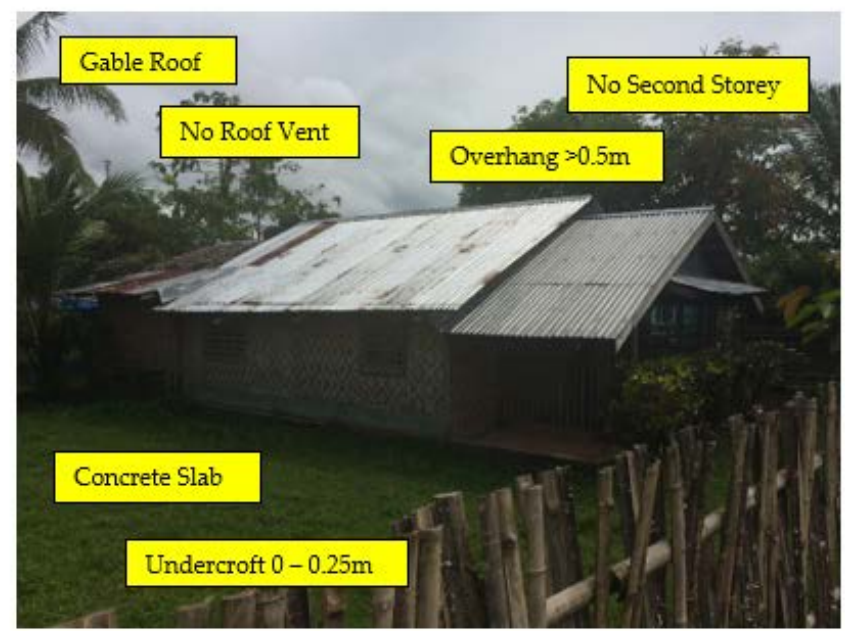

Vulnerability Ratings
F1: 1.0
F2: 1.0
F3: 1.0
Cum_Flood: 1.0
W1: 1.0
W2: 1.0
W3: 1.0
Cum_Wind: 1.0
Total Vulnerability: 1.0

Figure 12. Example high vulnerability shelter from Badiangay.

In addition to individual building assessment, the vulnerability of the community of shelters in a given location was measured by looking at the surveyed buildings collectively and identifying the proportion of low to high vulnerability characteristics across all buildings. This is depicted, for the three locations in this study, in Figures 13 and 14 for flood and wind hazard, respectively, while in the charts, a darker shade indicates higher vulnerability. The charts show the proportion of buildings surveyed in each location that fall into increasing vulnerability categories, increasing from 1 (lowest vulnerability) to 2 or 4 (highest vulnerability), depending on the number of increments for the indicator.
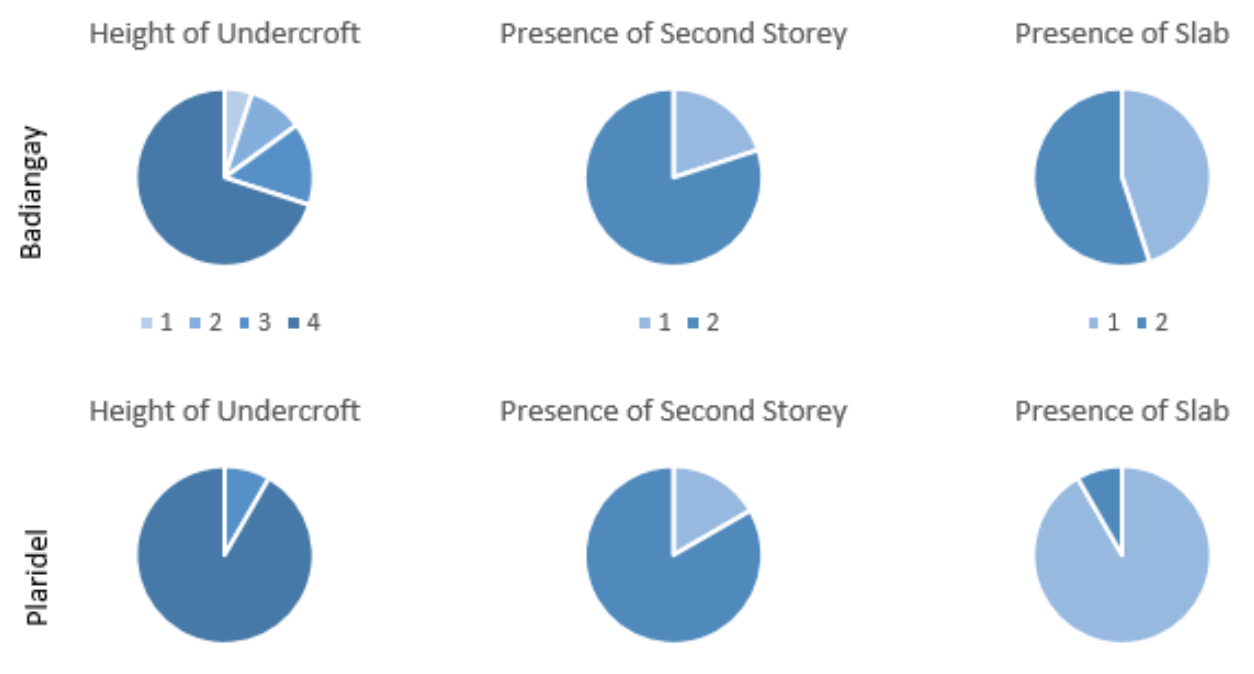

$=1=2-3=4$

$=1=2$

$\| 1=2$

Height of Undercroft

Presence of Second Storey

Presence of Slab
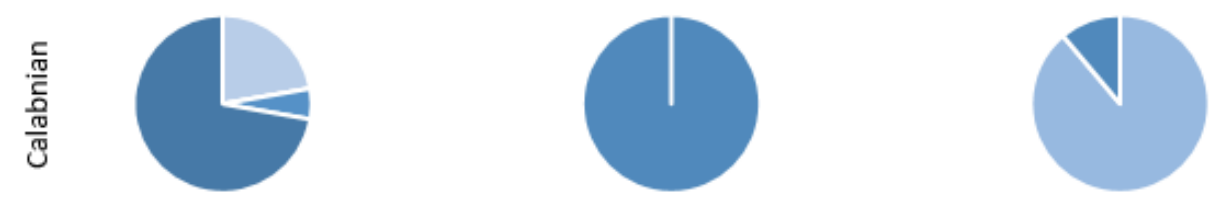

$=1=2 \cdot 3=4$

$$
\text { - } 1 \text { - } 2
$$

- 1 .

Figure 13. Vulnerability indicator distribution for flood hazard across three locations: Badiangay, Plaridel, and Calabnian. 


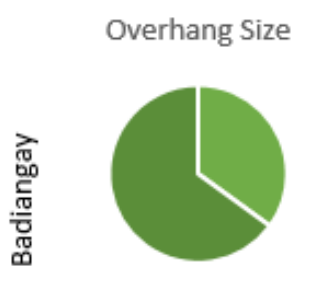

- 1 - 23

Overhang Size

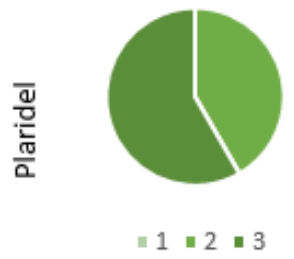

Overhang Size

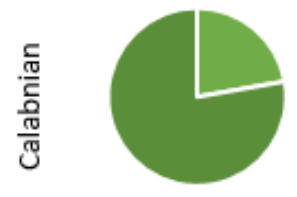

$=1 \cdot 2 \cdot 3$
Roof Shape

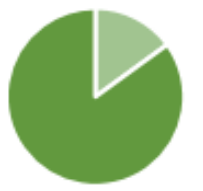

$=1-2$

Roof Shape

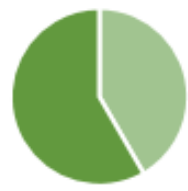

$\square 1=2$

Roof Shape

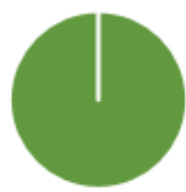

$\because 1 \pm 2$
Presence of Roof Vent

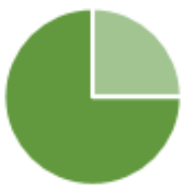

= 1 - 2

Presence of Roof Vent

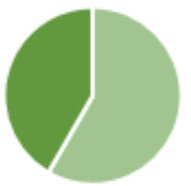

$\| 1 \cdot 2$

Presence of Roof Vent

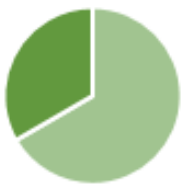

- 1 - 2

Figure 14. Vulnerability indicator distribution for wind hazard across three locations: Badiangay, Plaridel, and Calabnian.

The method pictorially describes the vulnerability at settlement scale for the individual indicators, and comparison of the charts shows which locations have a higher proportion of vulnerable buildings. For example, Badiangay has the highest proportion of vulnerable stock when considering the presence of a concrete slab in response to the flood hazard. The charts also show which indicators are more prevalent at high vulnerability states across all sites. For example, undercroft heights are dominant at the highest vulnerability level across all three sites, unlike the other two indicators. This method of display offers the opportunity to take an overview of the state of vulnerability of a given site or collection of sites, an important factor in the understanding the relative risk to different locations.

This is a first step toward a robust multi-hazard physical vulnerability assessment of vernacular timber structures prevalent in rural Philippines. Further iterations of the method will look to expand the number of externally visible indicators to incorporate more aggregated measure of vulnerability. Such indicators could include the plan shape of the building which affects local wind pressure distributions, roof pitch which has been shown to affect peak pressure and height to volume ratio of the building. Providing the surveying effort allows for feasible collection of robust data (in terms of sample size and completeness), further more detailed structural measures could also be incorporated, such as the presence of bracing which contributes to wind resistance.

An additional step would be to collate the individual vulnerability factors (VF's) into a single rating for all indicators, by summing and then normalising the result, bringing the method in line with other multi-hazard assessments that make use of this methodology [55]. This would incorporate the positive and negative effects of individual features in respect to both hazards and sum to give a measure of the cumulative effect of each. From this a single numerical value for an individual building can be obtained, such as would be used for the computation of risk, as described further in the next section. 


\subsection{A Risk-Based Approach for Disaster Shelter Practitioners}

The final stage of the assessment is to consider the vulnerability and hazard together in order to begin to describe the risks. A pictorial and matrix approach is proposed and discussed here, which is intended to be both simple to produce and easily explained to local communities. First, the vulnerability ratings (VR) for each of the buildings on a given site are grouped into low, medium, and high classes. A VR of between 0 and 0.33 is classed as low (1), between 0.34 and 0.66 as medium (2), and between 0.67 and 1 as high (3).

Second, the hazard severity for each building is additionally grouped into low (L), moderate (M), and high (H). For the Mines and Geoscience Bureau (MGB) maps used here [49-52], the high and very high flood hazard levels were combined into a single 'high' band of hazard severity. In general, the hazard rating from the MGB and Project NOAH maps were similar (e.g., Figure 8). However, where there was a discrepancy, the highest rating out of the two maps was chosen. The hazard and vulnerability levels for each building are then combined to provide a measure of the risk using a $3 \times 3$ matrix, offering nine different risk classifications for any given building on the site from L1 through to H3 (Figure 15A,B).
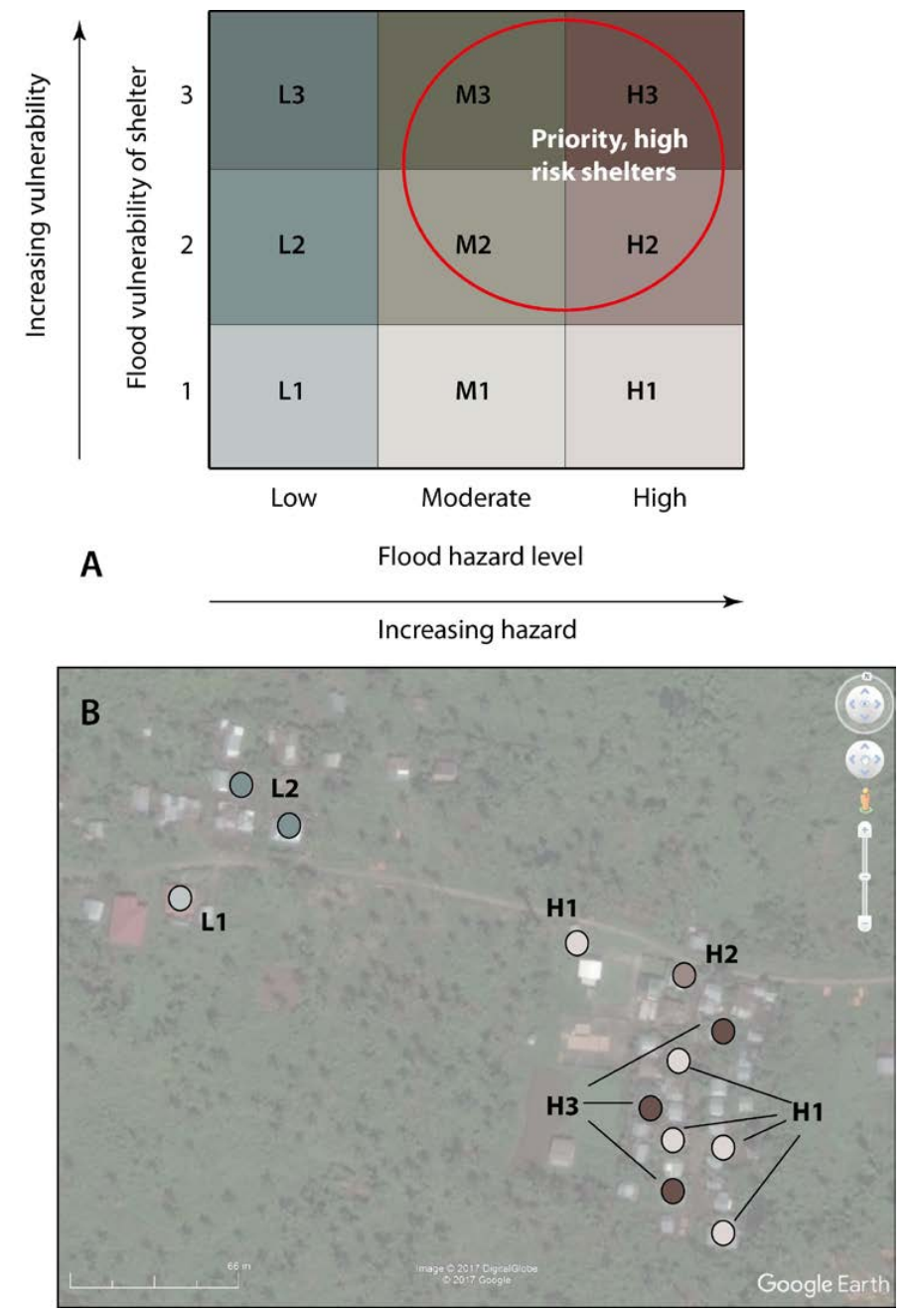

Figure 15. (A) Illustration of shelter risk matrix for flooding hazard. Shelters that score in the lower left corner are considered lower risk, whereas shelters that score in the upper right corner are considered high risk, priority buildings. (B) Using the risk matrix for flood hazard in for selected buildings in Calabnian. Base image from DigitalGlobe (11 December 2014) courtesy of Google Earth. Ongoing or future shelter assistance would be best targeted on houses scoring H3. 
As an example of the model, the flood risk matrix is applied to the site of Calabnian. The above vulnerability method is applied, and the shelters across the site assigned with a low, medium, or high flood vulnerability rating. Likewise, the flood hazard is assessed, and the same shelters are identified as lying within low, moderate or high hazard areas. These two factors are then combined and used to classify the risk level for each individual shelter at the site, as depicted in Figure 15b. The risk map shows that the collection of houses to the bottom right is at far greater risk than those to the top left. This is as a result of the change in flood hazard between these locations, highlighting that, within a single settlement, significant impact can be had on property risk as a result of changing flood hazard conditions. In the high risk zone, which has a constant flood hazard level, a differentiation between property vulnerability is also demonstrated by the range of risk ratings (H1-H3). This demonstrates that the vulnerability rating of buildings also informs on the overall risk to homes and communities.

This identification gives shelter practitioners an opportunity to highlight to communities how best to address these risks through adapting their shelters to be more resilient. This could be through movement of their shelters to a site with a lower flood hazard or through modification of the design of their shelter to reduce the vulnerability to flood inundation. The application of the risk to wind hazards is less applicable to the matrix approach at this stage of the work, as the wind hazard has a single severity rating at the scale of individual communities. Nevertheless, the wind vulnerability assessment can be used to support and inform practitioner advice for those communities recovering following a typhoon. In either case, a clear and simple message can be translated to communities, thus promoting a helpful geoscience and engineering-informed intervention by shelter practitioners seeking to assist safer, more resilient recovery in flood- and typhoon-affected communities.

\section{Discussion}

The process presented in this paper provides stakeholders, be they homeowners or aid organisations, with necessary information in the format needed to approach the process of disaster recovery from a risk reduction perspective. The use of hazard mapping available from MGB and Project NOAH provides a measure of flood hazard severity that has institutional approval at national level, offering reliable datasets that additionally promote the growth of risk reduction strategies from within the country. The wind hazard data has been ratified by the global community working in risk reduction, and provides further reliable input to the consideration of risk in relation to typhoon effects.

The site data collection enables the approach to incorporate the experience and knowledge of the local communities and importantly expands the work to take account of local conditions in relation to geoscience and geomorphology. This enables the appraisal of the risk to account for local evidence for geohazards, deepening the understanding of that risk and ultimately providing a more meaningful measure of risk for the communities. This is a key aspect of the work, and further integration of local knowledge into the hazard and risk assessment is a significant future aspiration for the project team.

The measuring of vulnerability in the manner set out here offers an opportunity for meaningful quantification driven by readily apparent building features that contribute to the overall vulnerability of the structure. As with any indicative method of vulnerability assessment there is an element of uncertainty regarding the measures used. The multi-hazard nature of typhoons adds to this in that structural modifications which reduce vulnerability to one hazard may not provide overall risk reduction, and this is an important consideration for the future. The method is not intended to be a substitute for a full mechanical or computational assessment of structural response. Rather, the intention is that by taking these first steps toward considering vernacular buildings such as those in rural Philippines as physically vulnerable assets, through the use of an appropriate and feasible framework, the longer-term goal of understanding the risk posed to them can begin to be met.

The bringing together of the hazard and vulnerability assessments into a single output that aims to describe the risk is in the first instance an exercise in communicating the science and engineering knowledge through a method that addresses the call from the global community to understand risk posed by natural hazards to settlements in low- and middle-income countries. The display of this 
knowledge through a mapping medium that incorporates vulnerability at individual building scale represents an important step in this process as it empowers the homeowner through identifying risk at an individual level. Further iterations of the vulnerability measures will provide greater detail to this process, as will incorporation of more extensive local knowledge regarding the hazards.

This work provides those who are involved in shelter aid and assistance in post-disaster contexts a demonstration of what a potential route to reducing future risks could look like. The implementation of such a method would require addressing challenges that are faced by those practitioners in this context. One such challenge is the changing nature of their work, which at different times in the aftermath of a disaster takes on a variety of roles. In the immediate aftermath, when buildings are being reconstructed or have been done so before their arrival, the implementation of risk reduction measures are more difficult, and it would not necessarily be feasible to incorporate a method such as that proposed here in the rapid assessments that take place at that time.

Where a method such as this has more significance is in the longer-term assistance programmes that are initiated, such as was the case in the Philippines where shelter programmes were in place for months and years after the disaster took place. In this context, the delivery of the BBS messages and associated education and training that takes place does offer an opportunity for risk reduction measures and advice to be implemented. The use of hazard scales derived from historic datasets, along with vulnerability assessments that can be demonstrated as being directly applicable to people's homes, provides a robust starting point in understanding the risk for both the practitioner and the community.

There is clear work to do in order to enable a method such as this to achieve its potential: for example, practical implications such as ensuring hazard maps are accessed by practitioners as they prepare to enter the disaster zone. Furthermore, the uptake of such an approach would require an investment by NGOs in the training and preparation of their shelter experts to allow them to embrace a more interdisciplinary, developed hazard and vulnerability assessment tool and further enhance its fitness-for-purpose within the shelter assistance community.

More detailed considerations include being able to incorporate the vulnerability assessment into the process of reconstruction, which will likely have started before practitioners arrive at the disaster. In this way the process needs to acknowledge that modifications may already have been made to the rebuilt structure, and understanding vulnerability requires consideration of what has already been changed, and what may change in the future as a result of BBS message education and promotion. By undertaking the process of assessing buildings in this way practitioners can better understand the context and respective vulnerabilities that households face as a result of the local construction practices and hazard awareness, and based on this understanding, advise for more resilient reconstruction.

In the immediate aftermath of the disaster, rapidly deployed temporary assistance does not allow for the detailed assessment required by this method. Rather, practitioners are there to provide cash, materials, information, and training, but essentially those rebuilding and choosing the materials are the disaster-affected households. Future development of the approach will need to address the fact that people's reconstruction practices are not always directly affected by technical knowledge, availability, and affordability of material or hazard awareness. Some of the vulnerabilities built in to people's homes are consequences of aesthetic preferences, culture, and/or proximity to livelihoods. Even the movement of a home from one area to another piece of land is rarely an option for most families. The influence that technical and risk-based advice may have on these choices is not always clear or direct. From the position of a shelter practitioner, the aim is to support informed choice for those who will be reconstructing anyway, using a framework that promotes long-term risk reduction.

Here, the authors address significant challenges for shelter reconstruction and recovery in post-flood and typhoon rural Philippines. Firstly, that delivering adequate and effective resilient construction advice for affected communities is difficult and secondly that the engineering and geosciences expertise has an important role to play in effectively evaluating the risks to structures and therefore providing advice on how to reduce vulnerability. In view of this, the study applies geoscience and engineering appraisal to the problem of promoting more resilient reconstruction in 
post-disaster contexts. By demonstrating how a practitioner might evaluate and assign risk levels to buildings in communities, derived from consideration of both hazard and vulnerability measures, this study may add to the work of existing shelter practice and build on the debate about the current use of engineering and geosciences disciplines in informing the resilient reconstruction of shelters in post-flood and typhoon contexts such as that of the Philippines.

\section{Conclusions}

The work described here has achieved the following:

- The setting out of flood and wind hazard scenarios for individual rural community locations, derived from national datasets and individual community experiences;

- The application of a method to understand hazard-specific physical building vulnerability of vernacular housing in the Philippines;

- $\quad$ simple, systematic, and objective means of identifying the flood risk posed to rural shelters within assisted communities in post-disaster contexts;

- Visual outputs that can be readily translated into information useful for local people and as such offer an opportunity to explore the communication of a risk-based approach to post-disaster interventions for both practitioners and affected communities alike;

- Presentation of a method that offers shelter practitioners the first steps toward a risk reduction approach to advising on recovery processes as part of Build Back Safer drives in post disaster contexts.

These tangible outputs address the globally recognized ambition of reducing disaster risk in middle- and low-income countries, especially through focused application of technical knowledge available within the geosciences and engineering communities. It is an invitation for shelter practitioners to explore how they might bring engineering and geoscience disciplines into their work and offers the geoscience and engineering communities a demonstration of how they might support practitioners and communities in this. The overriding ambition is to prepare communities for future major hazard events and seek greater involvement in reconstruction processes of interdisciplinary risk reduction measures and approaches.

Acknowledgments: This work was enabled through the NERC-funded Grant NE/P016200/1 titled "Promoting Safer Building" and a programme of work funded by CARE UK (http:/ / promotingsaferbuilding.org). The authors thank and acknowledge the support of researchers at the Overseas Development Institute (Twigg, Lovell), CARE UK (Flinn, Schofield), BGS (Sargeant), Loughborough University (Dijkstra), and UCL (Rossetto, D'Ayala). The support of CARE International practitioners and researchers within the Philippines was also gratefully received during the field work phase.

Author Contributions: All authors contributed to the design and performance of the field study; Victoria Stephenson and Andrew Finlayson. analyzed the data; Luisa Miranda Morel contributed to the analysis; all authors contributed to the paper, and Victoria Stephenson coordinated the paper.

Conflicts of Interest: The authors declare no conflict of interest.

\section{References}

1. Philippine Atmospheric, Geophysical and Astronomical Services Administration (PAGASA). 2017 Annual Tropical Cyclone Tracks; Philippine Atmospheric, Geophysical and Astronomical Services Administration, 2017. Available online: https:/ / www1.pagasa.dost.gov.ph/index.php/tropical-cyclones/annual-tropicalcyclone-tracks (accessed on 5 October 2017).

2. Sendai Framework for Disaster Risk Reduction 2015-2030, United Nations, 2015. Available online: https:/ / www.unisdr.org/we/coordinate/sendai-framework (accessed on 24 January 2018).

3. World Bank Data on Philippines. Available online: https://data.worldbank.org/country/philippines (accessed on 30 January 2018).

4. Global Assessment Report, UNISDR, 2015. Available online: https://www.unisdr.org/we/inform/gar (accessed on 24 January 2018). 
5. Wisner, B.; Blakie, P.; Cannon, T.; Davis, I. At Risk: Natural Hazards, People's Vulnerability and Disasters, 2nd ed.; Routledge: London, UK, 2004; ISBN 9780415252164.

6. Dodman, D.; Francis, K.; Hardoy, J.; Johnson, C.; Satterthwaite, D. Understanding the Nature and Scale of Urban Risk in Low- and Middle-Income Countries and Its Implications for Humanitarian Preparedness, Planning and Response; Synthesis Report; UK Government Department for International Development, International Institute for the Environment and Development: London, UK, 2012.

7. Baker, J. Climate Change, Disaster Risk and the Urban Poor: Cities Building Resilience for a Changing World, 1st ed.; The World Bank: Washington, DC, USA, 2012; ISBN 978-0-8213-8845-7.

8. Pelling, M. The Vulnerability of Cities: Natural Disasters and Social Resilience; Earthscan: Abingdon, UK; Oxford, UK, 2003; ISBN 978-1853838309.

9. Adelekan, I.; Johnson, C.; Manda, M.; Matyas, D.; Mberu, B.; Parnell, S.; Pelling, M.; Satterthwaite, D.; Vivekananda, J. Disaster risk and its reduction: An agenda for urban Africa. Int. Dev. Plan. Rev. 2015, 37, 33-43. [CrossRef]

10. Parvin, G.A.; Reazul Ahsan, S.M.; Shaw, R. Urban Risk Reduction Processes in Bangladesh. In Disaster Risk Reduction Approaches in Bangladesh; Shaw, R., Mallik, F., Islam, A., Eds.; Springer: Tokyo, Japan, 2013; pp. 235-257. ISBN 978-4-431-54251-3.

11. Kruger, F.; Bankoff, G.; Cannon, T.; Orlowski, B.; Schipper, E. Cultures and Disasters: Understanding Cultural Framing in Disaster Risk Reduction; Routledge: Abingdon, UK, 2015; ISBN 978-0-415-74558-1.

12. Shaw, R.; Uy, N.; Baumwoll, J. Indigenous Knowledge for Disaster Risk Reduction; UNISDR: Geneva, Switzerland, 2008.

13. Alcantara-Ayala, I.; Goudie, A.S. Geomorphological Hazards and Disaster Prevention, 1st ed.; Cambridge University Press: Cambridge, UK, 2010; ISBN 978-0-521-76925-9.

14. Slater, L.J.; Singer, M.B.; Kirchner, J.W. Hydrologic versus geomorphic drivers of trends in flood hazard. Geophys. Res. Lett. 2015, 42, 370-376. [CrossRef]

15. Yumul, G.P., Jr.; Servando, N.T.; Suerte, L.O.; Magarzo, M.Y.; Juguan, L.V.V.; Dimalanta, C.B. Tropical cyclone-southwest monsoon interaction and the 2008 floods and landslides in Panay island, central Philippines: Meteorological and geological factors. Nat. Hazards 2012, 62, 827-840. [CrossRef]

16. Chigira, A.; Tsou, C.Y.; Matsushi, Y.; Hiraishi, N.; Matsuzawa, M. Topographic precursors and geological structures of deep-seated catastrophic landslides caused by Typhoon Talas. Geomorphology 2012, 201, 479-493. [CrossRef]

17. Brill, D.; May, S.M.; Engel, M.; Reyes, M.; Pint, A.; Optiz, S.; Dierick, M.; Gonzalo, L.A.; Esser, S.; Bruckner, H. Typhoon Haiyan's sedimentary record in coastal environments of the Philippines and its palaeotempestological implications. Nat. Hazards Earth Syst. Sci. 2016, 16, 2799-2822. [CrossRef]

18. Sanyal, J.; Lu, X.X. Remote sensing and GIS-based flood vulnerability assessment of human settlements: A case study of Gangetic West Bengal, India. Hydrol. Process. 2005, 19, 3699-3716. [CrossRef]

19. Osti, R.; Tanaka, S.; Tokioka, T. Flood hazard mapping in developing countries: Problems and prospects. Disaster Prev. Manag. Int. J. 2008, 17, 104-113. [CrossRef]

20. Abon, C.; David, C.P.C.; Tabios, G.Q. Community-based monitoring for flood and early warning system: An example in central Bicol River basin, Philippines. Disaster Prev. Manag. Int. J. 2012, 21, 85-96. [CrossRef]

21. $\mathrm{Pu}, \mathrm{R}$. A Special Issue of Geosciences: Mapping and assessing natural disasters using geospatial technologies. Geosciences 2017, 7, 4. [CrossRef]

22. Mas, E.; Brickaer, J.; Kure, S.; Adriano, B.; Yi, C.; Suppasri, A.; Koshimura, S. Field survey report and satellite image interpretation of the 2013 Super Typhoon Haiyan in the Philippines. Nat. Hazards Earth Syst. Sci. 2015, 15, 805-816. [CrossRef]

23. Rabonza, M.L.; Felix, R.P.; Lagmay, A.M.; Eco, R.N.; Ortiz, I.J.; Aquino, D.T. Shallow landslide susceptibility mapping using high-resolution topography for areas devastated by super typhoon Haiyan. Landslides 2016, 13, 201-210. [CrossRef]

24. Lagmay, A.M.; Racoma, B.A.; Aracan, K.A.; Alconis-Ayco, J.; Saddi, I.L. Disseminating near-real-time-hazards information and flood maps in the Philippines through Web-GIS. J. Environ. Sci. 2017, 59, 13-23. [CrossRef] [PubMed] 
25. Paz-Alberto, A.M.; Ramos, G.N.; Espiritu, J.A.; Mapanao, K.M.; Lao, R.B. Exposure and vulnerability assessment of buildings extracted from lidar derived datasets Bucao River floodplains, Zambales, Philippines. In Proceedings of the Fifth International Conference on Remote Sensing and Geoinformation of the Environment, Paphos, Cyprus, 20-23 March 2017; Volume 10444.

26. Adger, W.N. Vulnerability. Glob. Environ. Chang. 2006, 16, 268-281. [CrossRef]

27. Nasiri, H.; Yusof, M.J.M.; Ali, T.A.M. An overview to flood vulnerability assessment methods. Sustain. Water Resour. Manag. 2016, 2, 331-336. [CrossRef]

28. Pita, G.; Pinelli, J.; Gurley, K.; Mitrani-Reiser, J. State of the art of hurricane vulnerability estimation methods: A review. Nat. Hazards Rev. 2014, 16. [CrossRef]

29. Chen, S.E.; Leeman, M.E.; Englaish, B.J.; Kennedy, A.B.; Masters, F.J.; Pinelli, J.P.; Pang, W.; Rullan-Rodriguez, J.A.; Satyanarayana, P.; Calvo, J.; et al. Basic structure system rating of post-Super Typhon Haiyan structures in Tacloban and East Guiuan, Philippines. J. Perform. Constr. Facil. 2016, 30. [CrossRef]

30. Hernandez, J.Y., Jr.; Aquino, R.E.R.; Pacheco, B.M.; Cruz, E.C. Damage caused by Typhoon Haiyan in the Philippines, review of structural regulations and practice and research developments in wind engineering. Wind Eng. JAWE 2015, 40, 270-274. [CrossRef]

31. Goyal, P.K.; Datta, T.K.; Vijay, V.K. Vulnerability of rural houses to cyclonic wind. Int. J. Disaster Resil. Built Environ. 2012, 3, 20-41. [CrossRef]

32. Alam, M.R.; Kaish, A.B.M.A.; Zain, M.F.M.; Dev, S.K.; Mahzabin, M.S. Vulnerability assessment and construction recommendations of local houses in the cyclone prone coastal areas of Bangladesh. Int. J. Disaster Risk Reduct. 2017, 21, 118-130. [CrossRef]

33. Campanero, R.; Egaro, V. Correlates of vulnerability: A quantified study of people's vulnerability on the impact of super typhoon Yolanda in Guiuan, Eastern Samar, Philippines. Imp. J. Interdiscip. Res. 2017, 3, 416-432.

34. Usamah, M.; Handmer, J.; Mitchell, D.; Ahmed, I. Can the vulnerable be resilient? Co-existence of vulnerability and disaster resilience: Informal settlements in the Philippines. Int. J. Disaster Risk Reduct. 2014, 10, 178-189. [CrossRef]

35. ARUP. Pakistan Shelter Guide: Design for Improved Flood Resilience in Sindh; ARUP: London, UK, 2017.

36. Promoting Safer Building: Supporting Self-Recovery after Disasters. Available online: promotingsaferbuilding.org (accessed on 10 December 2017).

37. GFDRR. Disaster Risk Reduction. Available online: https://www.gfdrr.org/sites/gfdrr/files/WB_UNDP_ PDNA_DRR_SP_FINAL.pdf (accessed on 30 January 2018).

38. CARE Philippines. Typhoon Haiyan Shelter Recovery Project Evaluation; CARE International: Manila, Philippines, 2015.

39. Global Shelter Cluster: 8 Build Back Safer Key Messages. Available online: https:/ /www.sheltercluster.org/ pacific/documents / 8-build-back-safer-key-messages-english (accessed on 25 March 2017).

40. Mayo, A. Cyclone Resistant Houses for Developing Countries; Building Research Station: Garston, UK, 1988.

41. Clayton, A.; Davis, I. Building for Safety Compendium: An Annotated Bibliography and Information Directory for Safe Building; Intermediate Technology Publications: London, UK, 1994.

42. Opdyke, A.; Javernick-Will, A.; Koschmann, M.; Moench, H. Characterizing Post-Disaster Shelter Design and Material Selections: Lessons from Typhoon Yolanda in the Philippines. In Proceedings of the Construction Research Congress, San Jose, CA, USA, 31 May-2 June 2016.

43. Wazed, M.A. Bangladesh Report 2013: Disaster Preparedness Response and Recovery; Department of Disaster Management (DDM), Ministry of Disaster Management and Relief (MoDMR): Dhaka, Bangladesh, 2014. Available online: https:/ / reliefweb.int/sites/reliefweb.int/files/resources/Bangladesh\%20Report\%202013. pdf (accessed on 29 January 2018).

44. Parrack, C.; Flinn, B.; Passey, M. Getting the message across for safer self-recovery in post-disaster shelter. Open House Int. 2014, 39, 47-58.

45. Global Shelter Cluster: Promoting Safer Building Working Group. Available online: https://www. sheltercluster.org/working-group/promoting-safer-building-wg (accessed on 10 December 2017). 
46. Twigg, J.; Lovell, E.; Schofield, H.; Miranda Morel, L.; Flinn, B.; Sargeant, S.; Finlayson, A.; Dijkstra, T.; Stephenson, V.; Albuerne, A.; et al. Self-Recovery from Disasters: An Interdisciplinary Perspective; Overseas Development Institute: London, UK, 2017; Available online: https://www.odi.org/sites/odi.org.uk/files/ resource-documents /11870.pdf (accessed on 29 January 2018).

47. NASA JPL. NASA Shuttle Radar Tomography Mission (SRTM) Global 1 Arc Second. Version 3. 2013; NASA LP DAAC. Available online: http:/ /dx.doi.org/10.5067/MEaSUREs/SRTM/SRTMGL1.003 (accessed on 10 December 2017).

48. NASA JPL. NASA Shuttle Radar Tomography Mission (SRTM) Global 3 Arc Second. Version 3. 2013; NASA JPL. Available online: http:/ /dx.doi.org/10.5067/MEaSUREs/SRTM/SRTMGL3.003 (accessed on 10 December 2017).

49. Mines and Geoscience Bureau (MGB). Detailed Landslide and Flood Hazard Map of Tacloban City and Santa Fe, Leyte, Philippines 3923-II-5 Badiangay Quadrangle; Department of Environment and Natural Resources-Mines and Geoscience Bureau (MGB), Lands Geological Survey Division: Quezon City, Philippines, 2015.

50. Mines and Geoscience Bureau (MGB). Detailed Landslide and Flood Hazard Map of Santa Fe, Palo and Alang-Alang, Leyte, Philippines 3923-II-9 Bulod Quadrangle; Department of Environment and Natural Resources-Mines and Geoscience Bureau (MGB), Lands Geological Survey Division: Quezon City, Philippines, 2015.

51. Mines and Geoscience Bureau (MGB). Detailed Landslide and Flood Hazard Map of La Paz, Burauen and Julita, Leyte, Philippines 3922-I-9 Calabnian Quadrangle; Department of Environment and Natural Resources-Mines and Geoscience Bureau (MGB), Lands Geological Survey Division: Quezon City, Philippines, 2015.

52. Mines and Geoscience Bureau (MGB). Detailed Landslide and Flood Hazard Map of Pastrana, Jaro and Alangalang, Leyte, Philippines 3913-II-12 Patong Quadrangle; Department of Environment and Natural Resources-Mines and Geoscience Bureau (MGB), Lands Geological Survey Division: Quezon City, Philippines, 2015.

53. Neussner, O. Residential Building Suitability Map for Leyte Island, Philippines; Deutsche Gesellschaft für Internationale Zusammenarbeit (GIZ) GmbH: Berlin, Germany, 2015; Available online: https: / www.gidrm. net/site/assets / files/1218/olaf_neussner-_2015.pdf (accessed on 10 September 2017).

54. Stephenson, V.; D'Ayala, D. A new approach to flood vulnerability assessment for historic buildings in England. Nat. Hazards Earth Syst. Sci. 2014, 14, 1035-1048. [CrossRef]

55. D’Ayala, D.; Galasso, C.; Putrino, V.; Fanciullacci, D.; Barucco, P.; Fanciullacci, V.; Bronzino, C.; Zerrudo, E.; Manolo, M.; Fradiquela, C.; et al. Assessment of the Multi-Hazard Vulnerability of Priority Cultural Heritage Structures in the Philippines. In Proceedings of the 1st International Conference on Natural Hazards and Infrastructure, Chania, Greece, 28-30 June 2016.

56. Kelman, I.; Spence, R. An overview of flood actions on buildings. Eng. Geol. 2004, 73, 297-309. [CrossRef]

57. Fernandez, R.D.A. A visual Dictionary on Filipino Architecture; University of Santo Tomas Publishing House: Manila, Philippines, 2015; ISBN 978-971-506-770-6.

58. Gavanski, E.; Kordi, B.; Copp, V.A.; Vickery, P.J. Wind loading on roof sheathing of houses. J. Wind Eng. Ind. Aerodyn. 2013, 114, 106-121. [CrossRef]

59. Prasad, P.; Uliate, T.; Rafiuddin Ahmed, M. Wind loads on low-rise building models with different roof configurations. Int. J. Fluid Mech. Res. 2009, 36, 231-243. [CrossRef]

60. Ahmad, S.; Kumar, K. Effect of geometry on wind pressures on low-rise hip roof buildings. J. Wind Eng. Ind. Aerodyn. 2002, 90, 755-779. [CrossRef]

61. Seifert, J.; Li, Y.; Axley, J.; Rasler, M. Calculation of wind-driven cross ventilation in buildings with large openings. J. Wind Eng. Ind. Aerodyn. 2006, 94, 925-947. [CrossRef]

(C) 2018 by the authors. Licensee MDPI, Basel, Switzerland. This article is an open access article distributed under the terms and conditions of the Creative Commons Attribution (CC BY) license (http://creativecommons.org/licenses/by/4.0/). 